\title{
Review Article \\ Fine Tuning Cell Migration by a Disintegrin and Metalloproteinases
}

\author{
D. Dreymueller, ${ }^{1}$ K. Theodorou, ${ }^{2}$ M. Donners, ${ }^{2}$ and A. Ludwig ${ }^{1}$ \\ ${ }^{1}$ Institute of Pharmacology and Toxicology, Uniklinik RWTH Aachen, Aachen, Germany \\ ${ }^{2}$ Department of Pathology, Maastricht University, LK Maastricht, Netherlands \\ Correspondence should be addressed to D. Dreymueller; daniela.dreymueller@rwth-aachen.de \\ and M. Donners; marjo.donners@maastrichtuniversity.nl
}

Received 13 October 2016; Accepted 22 December 2016; Published 5 February 2017

Academic Editor: Anshu Agrawal

Copyright (C) 2017 D. Dreymueller et al. This is an open access article distributed under the Creative Commons Attribution License, which permits unrestricted use, distribution, and reproduction in any medium, provided the original work is properly cited.

Cell migration is an instrumental process involved in organ development, tissue homeostasis, and various physiological processes and also in numerous pathologies. Both basic cell migration and migration towards chemotactic stimulus consist of changes in cell polarity and cytoskeletal rearrangement, cell detachment from, invasion through, and reattachment to their neighboring cells, and numerous interactions with the extracellular matrix. The different steps of immune cell, tissue cell, or cancer cell migration are tightly coordinated in time and place by growth factors, cytokines/chemokines, adhesion molecules, and receptors for these ligands. This review describes how a disintegrin and metalloproteinases interfere with several steps of cell migration, either by proteolytic cleavage of such molecules or by functions independent of proteolytic activity.

\section{Principles of Cell Migration}

Cell migration is a critical step in the homeostatic and inflammatory trafficking of immune cells, the migration of cells during embryogenesis, in regenerative processes such as wound healing, in tissue homeostasis, and also in the development of diseases such as cancer [1]. Dysregulation in migration can result in severe peri- or postnatal defects such as the neural tube defect [2], heart abnormalities, and defective lymphopoieses $[3,4]$. Further, in the adult organism, several pathologies are linked to alterations in migration, including inflammatory disorders such as rheumatoid arthritis and multiple sclerosis, vascular diseases [5], in which immune cells promote the inflammatory process [6], delay of wound closure, and tumor metastasis formation [7]. The list of migrating cell types is long differing in their form and speed of migration including immune cells, epithelial cells, endothelial cells, smooth muscle cells, pericytes, and neural cells. The exact mechanisms of cell migration can differ especially between rapidly migrating leukocytes and tissue cells. However, the involved surface molecules, the signal transduction pathways, and the underlying molecular machinery show a considerable degree of overlap in all motile cells.

On the migrating cell itself, a well-orchestrated sequence of single steps can be observed such as polarity changes, protrusion and retraction, and loose and firm adhesion to other cells or the extracellular matrix (ECM). Leukocytes and also cancer cells are capable of transmigrating through the tissue layers including endothelium or epithelium [7]. This also involves interaction with these tissue layers, which often regulate adhesion and junction molecules, thereby increasing permeability of the cell layer [8] as well as transmigration of the migrating cells. The polarizing and initiating stimulus can be of various nature: chemotactic (i.e., chemoattractants and morphogens) [1]; haptotactic (i.e., varying substrate concentrations in wound healing, angiogenesis, and metastasis) [9]; mechanotactic (i.e., loss of cellcell contacts in wound healing or metastasis) [10]; durotactic (i.e., varying rigidity) [11]. Polarization is accompanied by the extension of generally formed pseudopods towards the direction of migration, driven by the rearrangement of the actin cytoskeleton [12]. The different protrusions mediate the interaction with surrounding tissue cells and the ECM 
and the formation of adhesive complexes. The presence of nascent adhesions and focal complexes are markers of fast migrating cells, whereas focal adhesions as more mature structures are inversely correlated with cell motility [13]. The most important common components of adhesive complexes are integrins as adhesion receptors. Integrins are cell specifically expressed and activated upon specific stimulation, thereby mediating leukocyte adhesion and transmigration [14]. Podosomes are found in fast moving cells such as macrophages, sharing similar structures with invadopodia of metastatic tumor cells [15]. Both include the redirection of integrin receptors and adhesion molecules to the leading edge of the migrating cells, while invadopodia further concentrate proteolytic components that degrade the surrounding matrix to facilitate transmigration [16]. Often, tissue or cancer cell migration requires the acquisition of a migratory phenotype. These phenotypic changes can be brought about by cytokines, growth, or differentiation factors. For example, repair processes involving tissue cell migration and also cancer cell migration can be initiated within the tissue layers by transforming growth factor (TGF) $\alpha$ and heparin-binding epidermal growth factor (HB-EGF) [17-19].

One of the most studied migratory events is the recruitment of immune cells from the blood to a site of inflammation, for example, caused by wounding or infection. Proinflammatory signals are released and relayed to the vascular endothelium, which exposes new adhesion molecules and receptors (e.g., E-selectin and P-selectin, vascular adhesion molecule 1 (VCAM-1), intercellular adhesion molecule 1 (ICAM-1), CXCL16, and CX3CL1 [20-23]). Immune cells are slowed down in migration and loosely adhering to the endothelium, rolling along the endothelium via the interaction of selectins with glycoprotein ligands, adhere more tightly via activated integrins, crawl on the endothelium probing for an extravasation point, and at last transmigrate through the endothelium.

Thus, for effective migration of immune cells, tissue cells or cancer cells several migratory steps need to be tightly coordinated. This involves the regulation of cytokines, growth factors, chemokines, adhesion molecules, and receptors for these ligands. Notably, many of these molecules are expressed as membrane-bound form and are functionally modulated by limited proteolysis close to the plasma membrane, a process called shedding. In many cases, members of the family of a disintegrin and metalloproteinases (ADAMs) mediate these shedding events. By this activity, ADAMs can interfere with several steps of cell migration. In addition, some ADAM family members can also regulate adhesion processes independently of any proteolytic activity.

\section{ADAM Proteases}

ADAM proteases belong to the class of metalloproteinases, which also comprises the matrix metalloproteinases (MMP) and a disintegrin and metalloproteinase with thrombospondin motif (ADAMTS). The ADAM family consists of 34 members, with 22 members described in humans [24, 25]. Most ADAMs are expressed as type I transmembrane surface proteins with a typical multidomain structure consisting of an N-terminal metalloproteinase domain, a disintegrin domain, a cysteine-rich domain, an EGF-like domain followed by a transmembrane domain, and a cytoplasmic tail (Figure 1). Most ADAMs are synthesized as proenzymes, in which the $\mathrm{N}$-terminal and inhibiting prodomain is released by furin-mediated cleavage during the maturation process. The zinc-dependent metalloproteinase domain mediates the proteolytic activity, which is only present in ADAM8, ADAM9, ADAM10, ADAM12, ADAM15, ADAM17, ADAM19, ADAM20, ADAM21, ADAM28, ADAM30, and ADAM33 [26]. ADAM2, ADAM7, ADAM11, ADAM18, ADAM22, ADAM23, ADAM29, and ADAM32 lack the consensus sequence HExGHxxGxxHD for metalloproteinase activity. Their function remains largely unknown but may include functions as adhesion molecules rather than as proteases. The cysteine-rich domain and disintegrin domain of most ADAM proteases are involved in substrate recognition and interaction with integrins and the extracellular matrix. ADAM10 and ADAM17 do not carry the typical EGF-like domain. Their cysteine-rich domain is followed by a so-called membrane-proximal domain as well as a small stalk region [27-29]. The cytoplasmic tail is very diverse in length and may be involved in signaling between the intracellular and extracellular portion as well as in assembling of cytoplasmic adaptor molecules. Some ADAM proteases exist not only as transmembrane proteins but also as soluble forms resulting from splice variants. These soluble forms of ADAM9, ADAM12, and ADAM28 lack the transmembrane domain and the C-terminal cytoplasmic tail [26].

Proteolytic activity has been reported for ADAM8, ADAM9, ADAM10, ADAM12, ADAM15, ADAM17, ADAM28, and ADAM33 [30]. The interaction partners and substrates of ADAMs are generally transmembrane surface proteins. It is important to note that, with only one reported exception [29], shedding occurs in cis and not in trans, meaning that substrate and protease have to be expressed on the same cell. The regulated proteolysis occurs close to the cell surface, resulting in the release of a soluble ectodomain and the production of a cell-associated fragment consisting of the transmembrane and the cytoplasmic domain. After this shedding process, the remaining fragment can undergo further regulated intramembrane proteolysis ("RIPping"), which has been reported for Notch [31]. ADAM activity can convert surface molecules into soluble agonists. By this, ADAMs critically drive the activity of cytokines (e.g., TNF), chemoattractants (e.g., CX3CL1), or growth factors (e.g., EGF). Further, released ectodomains can act as antagonists and sequester soluble ligands (e.g., TNFR). Shedding of a receptor or adhesion molecule (e.g., L-selectin) can lead to reduced responsiveness (e.g., VEGFR2) or cell adhesion (e.g., RAGE, L-selectin). Moreover, proteolytic release of an adhesion molecule bound to its receptor can result in detachment of adherent cells. Finally, cytoplasmic fragments released by RIPping may function as transcription factors (e.g., Notch). Notably, ADAMs can directly interact with adhesion molecules and extracellular matrix proteins (e.g., collagen). This interaction involves the disintegrin 


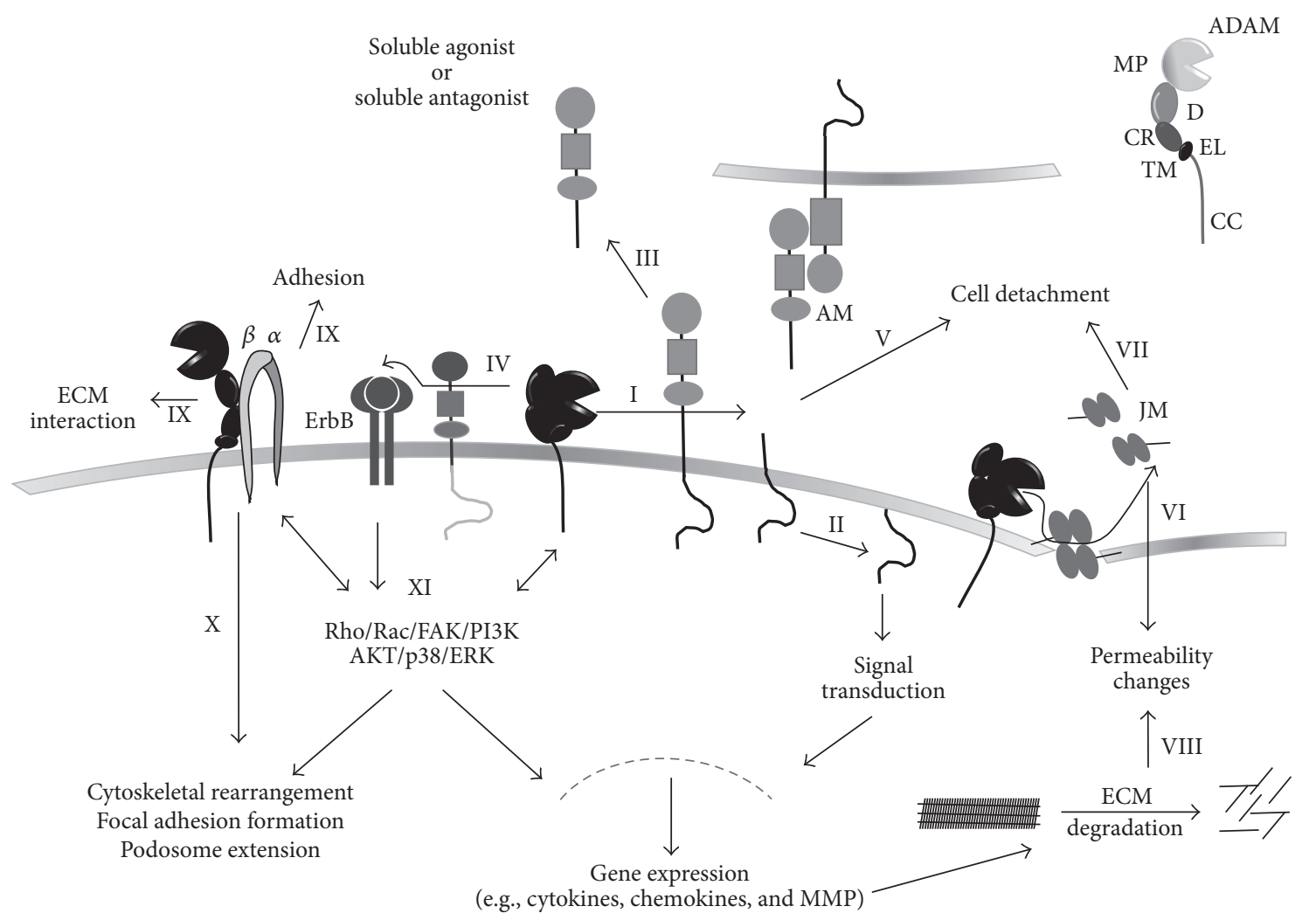

FIGURE 1: Catalytic and noncatalytic functions of ADAM proteases facilitating cell migration. ADAM proteases interfere with distinct steps of cell migration via a number different effector molecules. This involves proteolytic cleavage or nonproteolytic interactions of the proteases. ADAMs consist of a C-terminal cytoplasmic tail (CC) followed by a transmembrane domain (TM), an EGF-like domain (EL), a cysteinerich domain (CR), and a disintegrin domain (D) and an extracellular metalloproteinase domain (MP) (ADAM). ADAM proteases cleave transmembrane surface molecules close to the plasma membrane, a process called shedding, requiring a zinc atom in the active site of the metalloproteinase domain (I). This results in the release of a soluble ectodomain and the production of a cell-associated fragment consisting of the transmembrane and cytoplasmic domain. The remaining fragment can undergo further regulated intramembrane proteolysis by $\gamma$ secretase (II) at last functioning as transcription factor (e.g., Notch). ADAM activity can be regulated by activation of a precursor protein (e.g., pro-MMP9). The released ectodomain may function either as agonist like the chemokine CXCL16 and the ErbB ligands HB-EGF and neuregulin or as antagonist like soluble JAM-A or RAGE (III). The release of ErbB ligands leads to transactivation of ErbB receptors in cis and trans (IV). The inactivation of ligands (i.e., adhesion molecules (AM)) can lead to the detachment of bound receptor complexes and attached cells (i.e., L-selectin, MAC-1) (V). The cleavage of junction molecules (JM, i.e., cadherins) results in changes of permeability (VI), facilitating the transmigration of inflammatory cells, the invasion of cancer cells, and the dissemination resulting in metastasis and angiogenic processes (VII). The permeability is further regulated by ECM degradation, by either direct action of ADAM proteases (i.e., ADAM9) or the regulation of MMPs (VIII). With their disintegrin-like domain, ADAMs can directly interact with adhesion molecules and ECM proteins (IX). The integrin (indicated by $\alpha / \beta$ ) interaction/activation results in cytoskeletal rearrangement, focal adhesion formation, and podosome extension (X). Integrin, ADAM activation, and ErbB receptor transactivation result in different signaling pathways including the activation of Rho, Rac, FAK, PI3K, AKT, p38, and ERK, all further regulating ADAM and integrin activity as well as gene expression (XI). The exact mechanism of cell migration can differ between rapidly migrating leukocytes and tissue cells. However, the involved surface molecules, the signal transduction pathways, and the molecular machinery show a considerable degree of overlap for the action of ADAM proteases in inflammatory cell recruitment, angiogenesis, reepithelialization, cancer cell detachment and adhesion, and the intra- and extravasation during metastasis.

domain and can promote cell-to-cell adhesion or strengthen barrier function of cell layers [32].

This broad activity requires a regulatory network to limit the proteases activity in space and time. It is not yet fully understood how the substrate selectivity of the single ADAM proteases is mediated, as the substrates do not seem to carry a distinct cleavage site $[33,34]$. Specificity is possibly mediated by the substrate binding pocket [35], by exosites such as the cysteine-rich domain [29], the juxtamembrane region, and the transmembrane domain [27, 36-38]. Further, involved signaling pathways [39] as well as changes in the membrane structure $[40,41]$ may influence ADAM substrate specificity. Regulation of ADAM protease activity can occur on various levels. Acute and chronic stimulation and the tumor environment have been shown to enhance ADAM protease gene expression $[32,42,43]$. The increase of gene expression and enzyme synthesis are rather slow regulators of shedding activity. Rapid regulation of proteolytic activity 
occurs on the posttranscriptional level including the removal of the inhibitory prodomain [44], changes in membrane distribution $[41,45]$, release and transport to the cell surface [46, 47], multimerization on the cell surface [48], autocatalytic activation [49], interaction with adaptor molecules, and conformational changes $[40,50,51]$. Recently, pseudoproteases of the rhomboid family, the inactive rhomboid (iRHOM) 1 and 2, have been discovered as adapter molecules of ADAM17 in the endoplasmic reticulum mediating the transport of the protease to the Golgi apparatus and the cell surface $[52,53]$. ADAM10 does not seem to interact with iRHOMs, but its surface expression strongly depends on tetraspanins of the TSPANC8 family [54, 55]. Interestingly, also ADAM17 is regulated by the tetraspanin CD9/TSPAN29 [56]. Since iRHOMs and tetraspanins are critical for ADAM activity on the cell surface, they very likely also interfere with ADAM-dependent mechanisms of cell migration. Furthermore, tissue inhibitors of metalloproteinases are well known to block ADAM proteases. TIMP-1 turned out to be a relevant inhibitor of ADAM10 [57], while TIMP-3 is more effective on ADAM17 [58]. Thus, regulation of TIMP1 or 3 also represents a means of controlling ADAM10- or ADAM17-mediated migratory processes. As discussed below, rapid posttranslational regulation of shedding events and long-term transcriptional induction of protease activity contribute to very basic migratory events involved in many different pathologies including inflammation, healing responses, and tumor metastasis.

\section{ADAM Functions in Leukocyte Migration}

As mentioned above, ADAM proteases may regulate cell migration either by their shedding activity or by the noncatalytic functions such as matrix and integrin interactions (Figure 1).

3.1. ADAM-Mediated Shedding in Leukocyte Migration. Leukocyte migration through tissue cells can depend not only on the proteolytic activity of ADAMs on the leukocytes themselves (see Table 1) but also on the ADAM protease activity on the tissue cells serving as substrate of cell migration (see Table 2).

In tissue cells transmigrated by leukocytes, ADAM10 and ADAM17 are the predominant proteases mediating shedding events that regulate leukocyte migration. Both endothelial and epithelial cells form a dense barrier to insure tissue integrity, which has to be opened transiently for transmigration. Upon stimulation with VEGF or thrombin, VE-cadherin is shed from the endothelial cell surface by ADAM10 and ADAM17 [59, 60]. The epithelial counterpart E-cadherin is solely shed by ADAM10 under physiological as well as pathological conditions [61]. Whereas shedding of VE-cadherin and E-cadherin has been shown to facilitate transmigration, the function of JAM-A is divergent. In its transmembrane form, JAM-A controls endothelial tight junction formation and contributes to leukocyte transendothelial migration $[62,63]$. In contrast, soluble JAM-A, predominantly released by $\mathrm{ADAM} 17$, was shown to reduce inflammatory cell recruitment both in vitro and in vivo, avoiding excessive infiltration [62]. Endothelial cells express the transmembrane chemokines CXCL16 and CX3CL1, which are upregulated under inflammatory conditions and constitutively and inducibly shed by ADAM10 and ADAM17 [22, $64,65]$. The transmembrane forms act as adhesion molecules, regulating the interaction of $\mathrm{T}$ lymphocytes and monocytes with tissue cells $[66,67]$, whereas the soluble variants act as chemokines, mediating the recruitment of CXCR6 or CX3CR1 expressing cells to the site of inflammation [68-73]. In inflammatory diseases, CX3CL1 is released not only by the endothelium but also by monocytes, T lymphocytes, and NK cells as shown for rheumatoid arthritis and cardiovascular diseases [74] and further enhances the recruitment of inflammatory cells from the circulation.

Meprins A and B, receptor for advanced glycation end products (RAGE), and activated leukocyte cell adhesion molecule (ALCAM (CD166)) are additional substrates shared by leukocytes and tissue cells in leukocyte migration. The meprins are shed by ADAM10 [75, 76] releasing a soluble form and facilitating migration through the cleavage of ECM molecules [77]. Additionally, meprin B cleaves E-cadherin, enhancing the induction of epithelial permeability [78], which could be negatively regulated by ADAM10. Trauma or inflammatory stimulation leads to the upregulation of RAGE on epithelial and endothelial cells, facilitating the adhesion and subsequent diapedesis of leukocytes [79, 80]. The function of RAGE on leukocytes appears to be celltype dependent. For macrophages, dendritic cells and $\mathrm{T}$ cells' influences only on activation, differentiation, and proliferation were reported. However, on neutrophils, RAGE was described as a chemotactic receptor interacting with high mobility box 1 protein (HMGB1) [81]. It is important to note that, in contrast to transmembrane RAGE, soluble RAGE released by ADAM10 functions as negative regulator of adhesion, blocking the activation of MAPK3 and PI3K. This inhibition of spreading and migration [82] could represent a mechanism for fine tuning of inflammatory cell recruitment. A similar function has been reported for soluble ALCAM, which may prevent the accumulation of premature tissue macrophages [83]. ALCAM is expressed on endothelial cells and upregulated upon inflammatory stimulation. Under homeostasis, peripheral blood monocytes and lymphocytes show only weak expression of ALCAM, whereas inflammation leads to upregulation of surface ALCAM, enabling homophilic (ALCAM-ALCAM) or heterophilic (ALCAM-CD6) interactions and supporting transmigration [83-85]. Especially on T lymphocytes, ADAM17-mediated ALCAM shedding appears to be essential for activated lymphocyte recruitment [84]. Clustering of ALCAM via upregulation of the tetraspanin CD9 was found to limit ADAM17-mediated shedding and lymphocyte recruitment [84].

Also on leukocytes themselves, ADAM10 and ADAM17 are the predominant shedding enzymes, influencing cellcell and cell-matrix interactions. Mac-1, which is expressed on monocytes, is one of the major interaction partners for endothelial expressed RAGE. Although Mac-1 cleavage by ADAM10 and ADAM17 was shown, only spatial and temporal ADAM17-dependent cleavage is essential for transendothelial migration of monocytic cells [86]. The function of L-selectin 


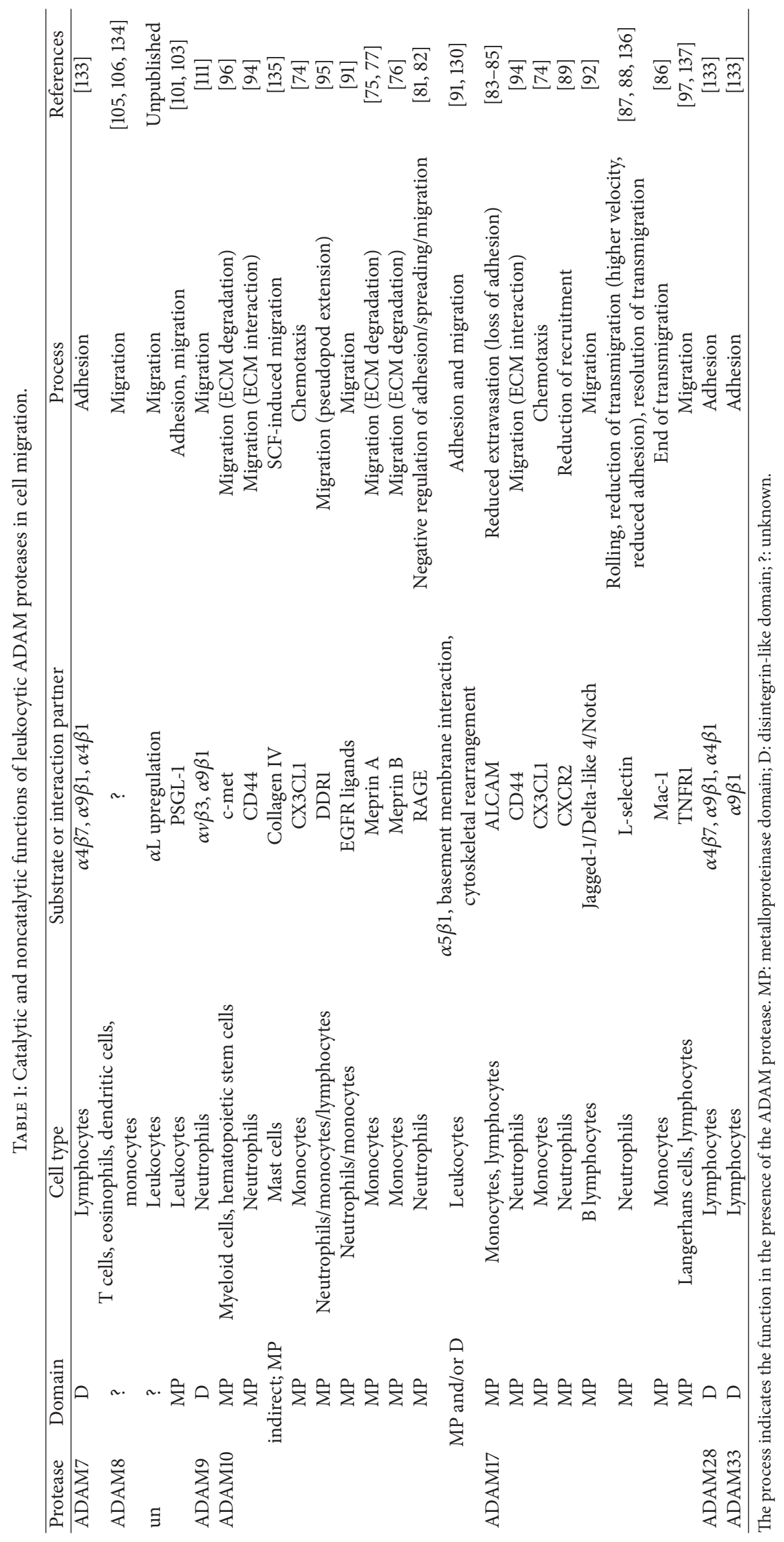




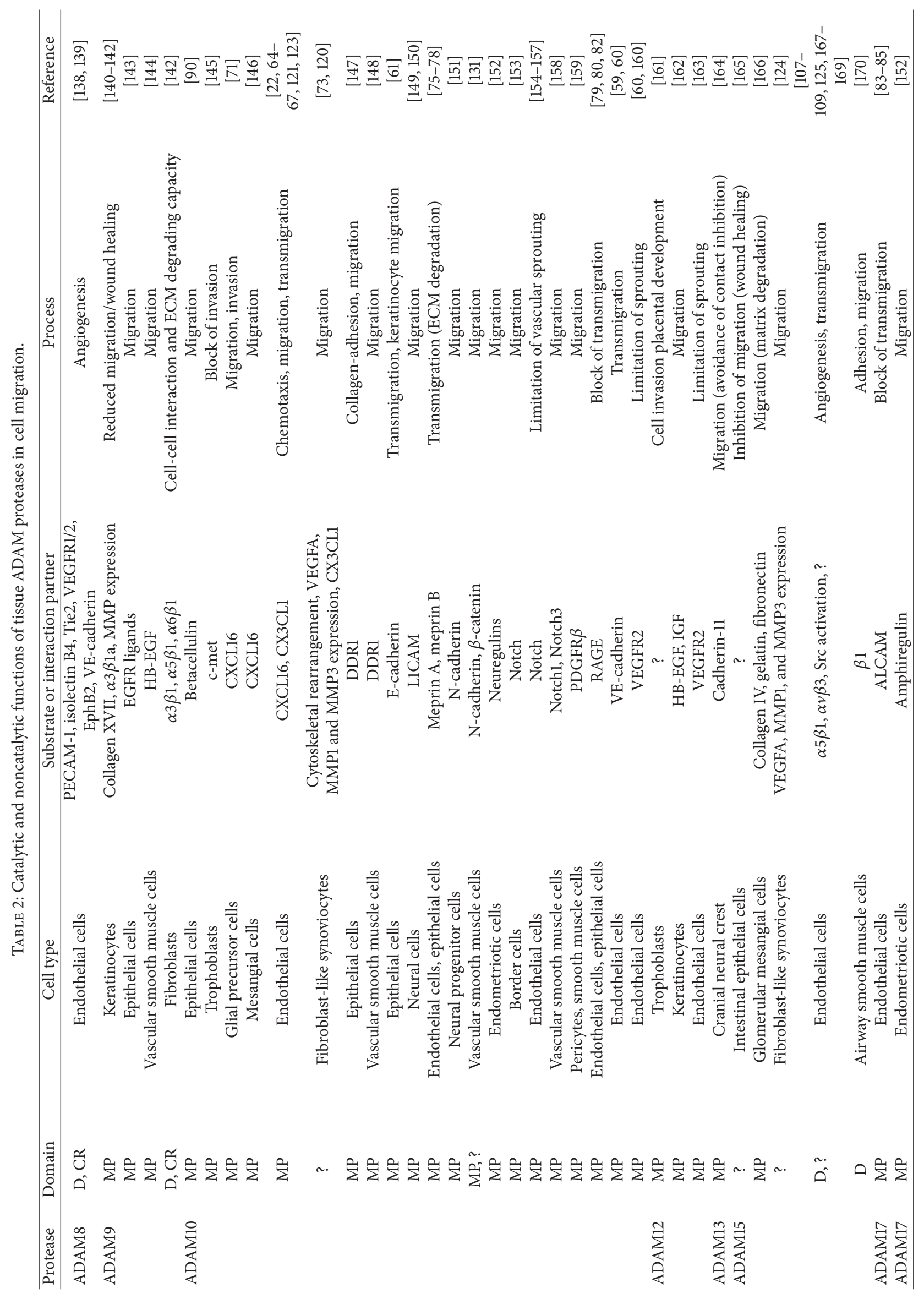




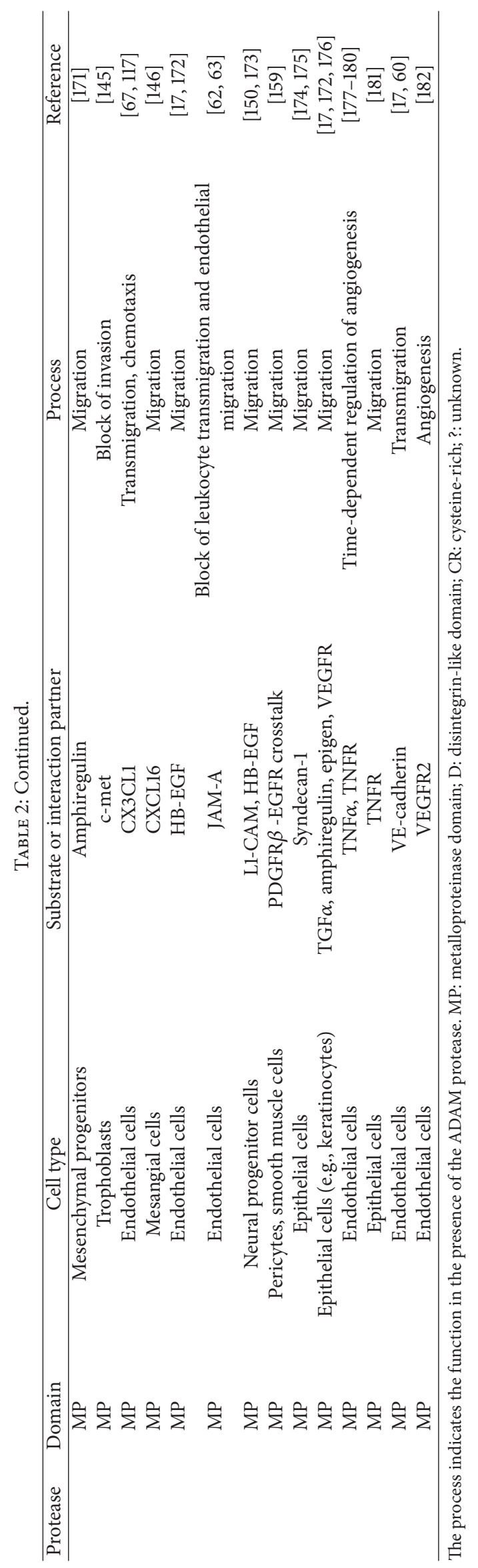


as adhesion molecule and interaction partner of E-selectin [87] has been extensively studied in neutrophil migration. L-selectin shedding by ADAM17 limits recruitment of neutrophils at early time points during inflammation. This is mediated by weakening of adhesion during leukocyte rolling along the endothelium leading to higher velocity of rolling leukocytes. In contrast to neutrophils, monocyte recruitment is not affected by L-selectin shedding [88]. ADAM17 mediated proteolytic shedding has been reported for CXCR2, the receptor for CXCL1 and CXCL8. Stimulation by lipopolysaccharide (LPS) or formyl peptide leads to enhanced CXCR2 shedding via ADAM17 and impairs neutrophil recruitment, which can be detrimental during excessive inflammation [89]. ADAM10 and ADAM17 are both responsible for the cleavage of epidermal growth factor receptor (EGFR) ligands, resulting in transactivation of EGFR [90]. However, for leukocyte migration, a distinct ligand has not been identified so far [91]. The migration of B lymphocytes towards Notch ligands was shown to depend on ADAM17 and $\gamma$-secretase activity, indicating a role of Notch receptor shedding in B cell migration [92]. It is not yet clear whether this could also account for other leukocyte populations. Involvement of cleavage events in the interaction with extracellular matrix proteins has been reported for CD44, the discoidin domain receptor 1 (DDR1), and the hepatocyte growth factor (HGF) receptor c-met. CD44 interacts with hyaluronic acid and is stimulus-dependently cleaved by either ADAM10 or ADAM17, involving $\mathrm{Ca}^{2+}$ influx or PKC and Rac activation [93]. Proteolysis of CD44 is essential for leukocyte migration as was exemplarily shown in liver neutrophil trafficking [94]. DDR1 is expressed on neutrophils, monocytes, and lymphocytes and mediates the adhesion to collagen. DDR1-collagen interaction results in DDR1 phosphorylation and subsequent shedding by ADAM10 allowing pseudopod extension and migration through p38 and NF-kB activation [95]. c-met surface expression and signaling are regulated by ADAM10- and ADAM17-mediated shedding. Migration of G-CSF mobilized myeloid cells and hematopoietic stem cells was shown to be in parts mediated via the HGF/c-met axis, increasing matrix degradation by enhancement of MMP expression [96]. In addition, cytokines can promote the migratory response of leukocytes. For example, migration of Langerhans cells in the skin and the mucosa largely depends on IL-1 and TNF $\alpha$ [97]. Also, for IL6, a promigratory function on T cells has been described [98]. This would imply that proteolytic shedding of cytokines like TNF $\alpha$ also regulates immune cell migration, and this activity could be counterregulated by receptor shedding of TNFR, IL1R, or IL6R [97, 99, 100]. However, linking investigations are still missing.

Besides ADAM10 and ADAM17, only ADAM8 has been shown to influence leukocyte migration by catalytic activity. The P-selectin glycoprotein ligand-1 (PSGL-1) mediates leukocyte rolling on the vascular endothelium in inflammation and is further essential for the migration of $\mathrm{T}$ lymphocytes under homeostatic conditions. ADAM8-dependent cleavage at the uropod loosens the initial binding and facilitates leukocyte migration [101-103]. However, besides ADAM8, also ADAM10 and the aspartyl protease BACE1 have been reported to cleave PSGL-1 [104], and the relative contribution of each protease remains unclear.

3.2. ADAM Noncatalytic Functions in Leukocyte Migration. In addition to the proteolytic shedding, many ADAMs display noncatalytic functions that can contribute to leukocyte migration. Such activity has been reported for ADAM8, ADAM9, ADAM10, ADAM15, ADAM17, ADAM19, ADAM28, and ADAM33. Most of these functions involve the regulation of integrins, directly affecting integrin-dependent adhesion as one of the first steps in leukocyte recruitment. Adhesive contacts via integrins are required for cell motility, but too tight adhesions prevent cell migration. Regulation of integrins can be a direct result of integrin binding to noncatalytic domains of ADAMs or result from the activation of signaling pathways leading to modulation of integrin expression and activity at the cell surface.

ADAM8 is essential for the clustering of $\beta_{1}$ integrin at the leading edge of migrating cells [48]. However, the function of this mechanism was not yet shown for leukocytic cells, but a promigratory/proasthmatic as well as antimigratory/antiasthmatic function of ADAM8 was reported in ovalbumin induced asthma $[105,106]$. ADAM15 is expressed on endothelial cells and enhanced during inflammatory processes, but circulating monocytes lack ADAM15 expression [107]. ADAM15 surface expression correlates with expression of $\alpha_{5}$ integrin, thereby influencing migration through adhesion [108]. Furthermore, the cytoplasmic tail of ADAM15 induces signaling processes including ERK1/2 and Src phosphorylation, which enhance endothelial permeability and monocyte transmigration $[107,109]$. ADAM28 in Jurkat cells can support $\alpha_{4} \beta_{1}, \alpha_{4} \beta_{7}$, and $\alpha_{9} \beta_{1}$ dependent adhesion, whereas ADAM33 can only interact with $\alpha_{9} \beta_{1}$ [110]. ADAM9 was shown to promote neutrophil activation and chemotaxis by engagement of $\alpha_{v} \beta_{3}$ and $\alpha_{9} \beta_{1}$ integrins within a hierarchical cross talk of integrins with CXCR2, involving GPCR, PI3K/AKT, and MAPK activation [111]. In myeloid cells, ADAM10 deficiency correlated with reduced surface upregulation of $\alpha_{5} \beta_{1}$ integrin upon CCL- 2 stimulation accompanied by impairment of p38 and Rho activation, cell-matrix interaction, and cytoskeletal rearrangement, resulting in inhibition of migration [91].

\section{Migratory Function of ADAM Proteases in Inflammatory Diseases}

The role of ADAMs in inflammatory diseases is still not fully understood. As described above, leukocytes and tissue cells express various ADAMs, which are likely to modulate cell migratory processes involved in the pathogenesis of many inflammatory diseases. As examples, we here briefly mention multiple sclerosis (MS), rheumatoid arthritis (AR), and atherosclerosis. We will here focus on the impact of ADAMs in cell migration. Other ADAM-dependent pathogenic mechanisms are reviewed elsewhere [112].

It was clearly shown that MMPs and TIMPs hold promigratory functions in MS, contributing to the pathogenesis of the disease [113]. However, ADAM proteases can be only 
indirectly linked to migratory processes so far. Investigation of postmortem brain sections of MS patients revealed that ADAM10 is expressed in astrocytes and sometimes in perivascular macrophages [114]. On the other hand, ADAM17 expression is associated with active MS lesions and gadolinium-enhancing lesions of relapsing-remitting MS patients [115], more specifically in blood vessel endothelial cells, activated macrophages, microglia, astrocytes [116], and invading $\mathrm{T}$ lymphocytes [114]. Invading $\mathrm{T}$ lymphocytes are one major source of TNF, which is shed by ADAM17 and associated with the relapse phase but would rather indirectly contribute to migratory processes. Further, CX3CL1, which is found in the brain and serum during MS, could fulfill different functions. On the one hand, CX3CL1 could activate and recruit circulating leukocytes, but, on the other hand, the adhesion to membrane-bound CX3CL1 could be blocked by its soluble form [117].

ADAM8, ADAM10, ADAM15, and ADAM17 have been shown to be upregulated in synovial fluid or tissue of RA patients compared to healthy individuals $[47,73,118,119]$. ADAM17 is responsible for the strong TNF release, which orchestrates the inflammatory response in RA. However, the TNF release influences the migratory process only indirectly. Expression levels of ADAM8 and ADAM10 in the synovial fluid correlate with the degree of joint inflammation and disease severity, respectively $[47,73]$. ADAM10 knockdown in $\mathrm{RA}$ reduced the LPS-induced migration and invasion of fibroblast-like synoviocytes (FLS) in vitro [120]. ADAM10 was clearly enhanced in biological fluids of RA patients, displaying a higher monocyte migratory activity [73]. Further, ADAM10 plays a proangiogenic role in RA indicated by an elevated tube formation of endothelial cells, which may be due CX3CL1 and vascular endothelial growth factor (VEGF) release [121]. One possible treatment of RA is tocilizumab, an antibody against the IL-6R. ADAM10 has been shown to be the major sheddase involved in induced shedding of IL$6 \mathrm{R}$ in human [122]. ADAM10 was shown to correlate with soluble CX3CL1, which was reduced upon antibody treatment and could serve as predictive marker [123]. However, the orchestration of the events and the contribution to cell migration of endothelial cells, FLS, and leukocytes in RA have still to be examined. Similar to ADAM10, knockdown of ADAM15 results in suppressed migration and invasion of FLS and silencing of ADAM15 in a rat model of CIA reduced the arthritis score and the extent of joint damage [124]. It was further shown that VEGF treatment enhances ADAM15 expression in synovial fibroblasts and in endothelial cells, if VEGFR2 expression was increased by TNF $\alpha$ stimulation. The overexpression of ADAM15 in RA synovium and the regulation through VEGF and VEGFR2 suggest a possible function of ADAM15 in angiogenesis in RA synovium [125].

ADAMs $8,9,10,12,15,17$, and 33 are expressed in human atherosclerotic lesions [126-128]; however, their causal role in the pathogenesis still remains ill-defined. Influences on involved migratory processes have been described only for ADAM10 and ADAM15 so far. The expression of ADAM10 in atherosclerotic lesions has been associated with human plaque progression and neovascularization [60, 127, 129]. Genetic ablation of ADAM10 or its inhibition reduces migration of endothelial cells, monocytes, macrophages, and vascular smooth muscle cells in vitro [60, 130, 131]. Further, the proatherosclerotic effect of MMP8 deficiency indicated by higher neointima formation was shown to be dependent on an ADAM10-, N-cadherin, and $\beta$-catenin-mediated pathway [131]. In addition, myeloid ADAM10 deficiency reduced expression of MMP9 and MMP13 as well as MMP2 gelatinase activity in macrophages. Further, ADAM10-deficient macrophages displayed a more anti-inflammatory phenotype with reduced migratory potential and less production of inflammatory mediators like TNF $\alpha$, IL-12, and NO upon LPS stimulation. These effects together led to higher plaque collagen content, resulting in a shift from inflammation to fibrosis in atherosclerosis due to altered ECM degradation and a shift in atherosclerotic plaque stability [130]. Furthermore, ADAM15 deficiency reduced atherosclerotic lesion progression in mice due to improved endothelial barrier function and reduced monocyte transmigration via Src activation [107].

\section{ADAM Proteases in Cell Migration during Healing Responses}

Wound healing is a highly dynamic process that involves the coordinated response of a considerable number of different cell lineages in an attempt to restore tissue integrity and homeostasis and is fundamentally similar among tissue types. The wound healing process is characterized by overlapping phases of inflammation, angiogenesis, reepithelialization, and resolution [132]. These steps involve proliferative as well as migratory responses of various tissue cells and leukocytes. The role of ADAMs in leukocyte recruitment has been discussed in the previous section. For the purpose of this review, we will focus on ADAM-dependent migration in angiogenesis and reepithelialization in this section (see Table 2).

5.1. Angiogenesis. During wound healing, the angiogenic process is initiated, which involves sprouting of wound edge capillaries followed by invasion into the site of damage. After a few days, the microvascular network is apparent throughout the wound. Sprouting angiogenesis is a multistep process involving endothelial cell proliferation and guided migratory invasion, which are regulated by proteolytic and nonproteolytic activities of ADAMs [221].

Endothelial cells in sprouts are guided by tip cells followed by a multicellular stalk of endothelial cells, which are interconnected by VE-cadherin at cell-cell junctions and successfully form an inner lumen. One of the best studied proangiogenic signals, namely, VEGF, controls the directed migration of the tip cells [222]. ADAM10, ADAM12, and ADAM17 have been shown to shed VEGFR2 upon activation in vitro, thereby limiting vascular sprouting [60, 160, 163]. However, ADAM10 and ADAM17 can have opposing effects on physiological angiogenesis in vivo. While genetic ablation or inhibition of ADAM10 increases vascular sprouting, most likely due to reduced shedding-mediated Notch activation, ADAM17 hypomorphic mice or inhibition of ADAM17 decreases angiogenesis in vivo [154-157, 223]. Interestingly, 
ADAM17 may exert both positive and negative effects on angiogenesis by timely release of TNF $\alpha$ [177] or its receptor TNFR. TNF $\alpha$ stimulation increased ADAM17 expression accompanied by increased shedding of TNFR, which could be a self-protective mechanism during prolonged immunostimulation [178]. Chronic exposure to TNF $\alpha$ inhibited angiogenesis, while a 2-3-day pulse stimulated angiogenesis by inducing a migratory tip-cell phenotype [179]. The different functions of TNF $\alpha$ signaling in ischemia-mediated angiogenesis could be in part explained by the opposite effects of TNFR1 and TNFR2. Stimulation of TNFR2 enhances endothelial cell migration, whereas TNFR1 inhibits migration [180]. However, it remains elusive how and when ADAM17 acts regulatory by the shedding of TNFRs in this process. Knockdown of ADAM17 reduces the amount of invading endothelial cells as well as the distance they covered in vitro [224]. Additionally, the migration of VEGF-A- or FGF7stimulated endothelial cells depends on EGFR activation via shedding of HB-EGF by ADAM17 [17, 172]. Migrating endothelial cells continuously extend and retract processes at the leading edge of the sprout [225]. Expression of a dominant negative mutant of ADAM17 increased the number of extending processes in endothelial cells, suggesting that ADAM17 is involved in proper retraction of these peripheral processes [224]. During angiogenesis, pericytes and smooth muscle cells are recruited to endothelial cells to stabilize developing blood vessels. This migratory process is mediated via the interaction of platelet-derived growth factor- (PDGF) $\mathrm{B}$ and its receptor PDGFR $\beta$. PDGFR $\beta$ is constitutively shed by ADAM10, whereas ligand-dependent activation does not lead to its own shedding but to stimulation of ADAM17dependent EGFR ligand shedding. This PDGFR $\beta$-EGFRsignaling axis was shown to be critical for PDGF-B stimulated cell migration [159]. Not only PDGFR $\beta$ but also DDR1 and its shedding may be important for angiogenesis. It was shown that DDR is critical in the regulation of attachment to collagen, chemotaxis, and MMP production in smooth muscle cells. Further, DDR1-null mice displayed lower intimal thickening after vascular injury [148]. As already mentioned before, DDR1 is shed by ADAM10 upon interaction with collagen [95]. Thus, it seems feasible that shedding of DDR1 by ADAM10 could be involved in smooth muscle cell migration and intimal thickening. However, this possibility still has to be investigated. Smooth muscle cell migration plays an important role in artery in-stent restenosis. Studies in minipigs and arterial smooth muscle cells indicated an involvement of ADAM10 in this process, partly mediated by Notch1 and Notch3 cleavage, resulting in nuclear translocation and downstream gene induction [158].

Both ADAM8 and ADAM15 are also implicated in angiogenesis. Overexpression of ADAM8 in vitro increases shedding of coexpressed proteins, including Tie2, VEGFR1 and VEGFR2, EphB2, and junctional molecules CD31 and VEcadherin [138]. Further, ADAM8 was shown to be associated with angiogenesis after spinal cord injury in mice [139]. The expression of ADAM15 is upregulated in endothelial cells during angiogenesis, where it can interact with $\alpha_{5} \beta_{1}$ and $\alpha_{v} \beta_{3}$ via its RGD motif [167], while ADAM15 knockout mice showed reduced angiogenic responses to hypoxia [168].
5.2. Reepithelialization. Upon injury, the regrowth of epithelium over a damaged area is pivotal in the repair phase of wound healing. Epithelial cells at the edge of the wounded tissue are instructed to loosen their cell-cell and cell-ECM contacts and migrate across the denuded area, while epithelial cells behind the leading edge start to proliferate until a new epithelium covers the damaged tissue [132].

E-cadherin, an adhesion molecule responsible for anchoring neighboring cells to one another, is cleaved by ADAM10, thereby decreasing cell-cell contacts and increasing migration of keratinocytes [61]. Studies have reported that ADAM9, ADAM10, and ADAM15 are able to cleave ECM substrates in vitro, including fibronectin, type IV collagen, and gelatin, thereby facilitating cell migration and release of sequestered growth factors to ECM proteins $[166,226,227]$. Shedding of collagen XVII from keratinocytes by ADAM9, ADAM10, and ADAM17 reduced migration due to the inhibitory effect of soluble collagen XVII on migration [140]. In line, wound repair was accelerated in ADAM9 deficient mice due to increased migration of keratinocytes and reduced constitutive shedding of collagen XVII [141]. Additionally, binding of ADAM9 to the integrin $\alpha_{3} \beta_{1}$ in keratinocytes increased MMP9 expression and subsequent cell migration [142]. EGFR ligands, including TGF- $\alpha$, HB-EGF, amphiregulin, betacellulin, and epiregulin, are expressed by keratinocytes and are key regulators of their migration [228], which can be processed into active soluble factors by ADAM9, ADAM10, and ADAM17 $[17,90,143,176]$. Deficiency of iRHOM2, which is critical for the maturation of ADAM17 in keratinocytes, reduces EGFR-dependent keratinocyte migration underlining the importance of ADAM17 for this response [38]. Besides the generation of soluble promigratory ligands, ADAM17 may also interfere with reepithelialization by the shedding of TNFR1 and TNFR2. Physiological levels of TNF $\alpha$ enhanced migration through TNFR2, whereas pathological levels inhibited wound closure through TNFR1 [181]. However, as already mentioned studies directly linking ADAM17, TNFR1 and migration are missing. Skin explants from ADAM12 knockout mice displayed increased migration of keratinocytes, potentially via shedding of HB-EGF and insulin-like growth factor (IGF) [162]. In contrast, wound healing in ADAM15 deficient mice was unaltered making ADAM15 dispensable for this process [229].

\section{ADAM Proteases in Cancer Cell Migration}

Tumor metastasis, the dissemination of cancer cells and subsequent outgrowth of secondary tumors at distant sites, is a major contributor to cancer morbidity and mortality. Metastasis is a multistep process involving the detachment of cancer cells from their surrounding tissue, the migration or invasion through the local extracellular matrix towards lymphatic or blood vasculature, the intravasation into the circulation, and lastly the extravasation at a distant tissue to establish a secondary tumor [230]. A number of ADAM proteins are (over)expressed in malignant tumors and have been shown to regulate several steps of the metastatic process, which will be discussed below (see Table 3 ). 


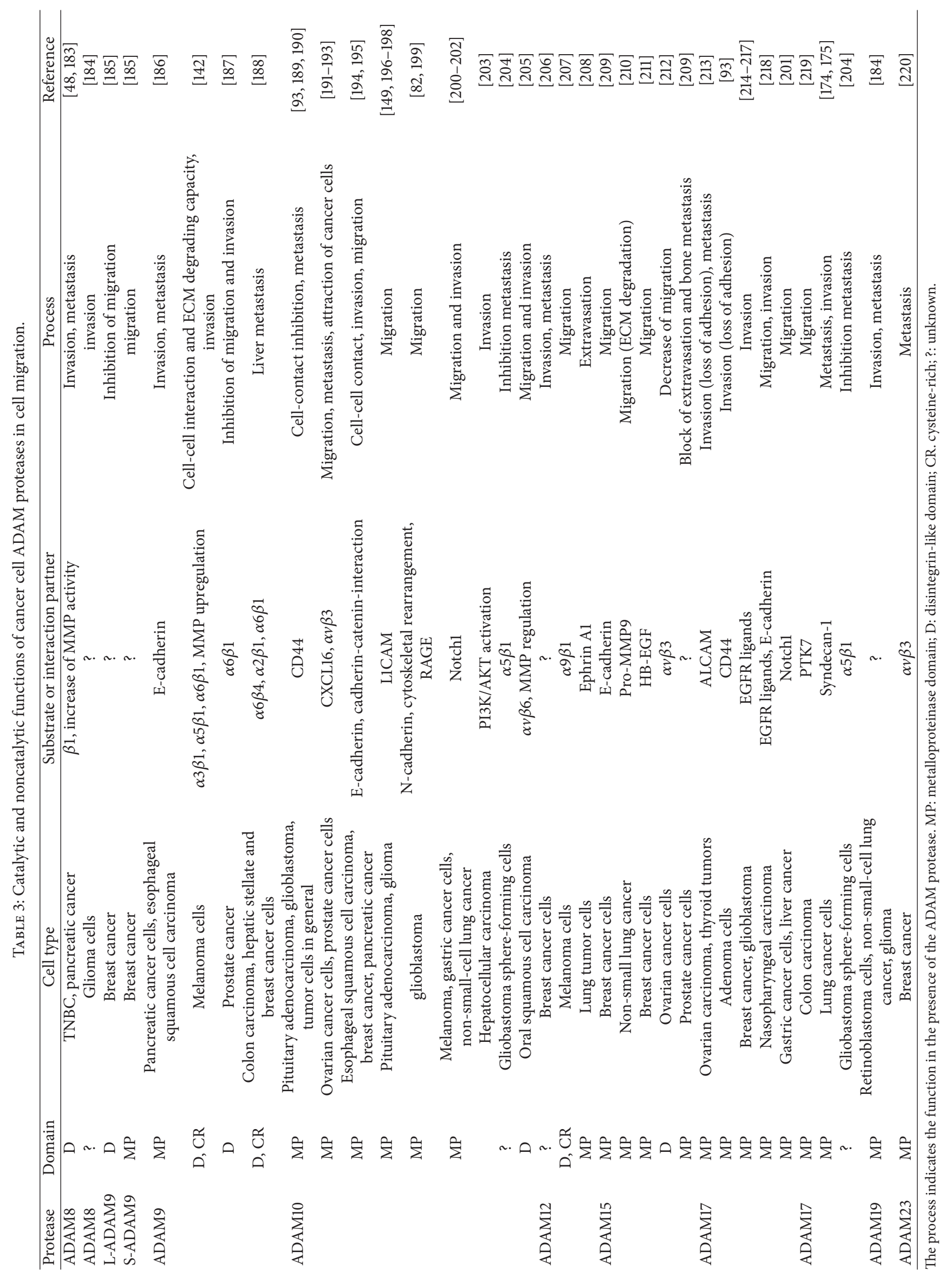


6.1. Detachment and Invasion of Cancer Cells. The initial process of tumor invasion involves loss of cell-cell adhesion and increased cellular mobility, resembling many features of epithelial to mesenchymal transition program during developmental processes (e.g., loss of E-cadherin expression, increased expression of $\mathrm{N}$-cadherin, and enhanced growth factor signaling) [231]. E-cadherin has been shown to be cleaved by ADAM9, ADAM10, and ADAM15 in cancer cells in vitro $[61,186,194,232]$. The cytoplasmic domains of cadherins interact with $\beta$-catenin, and reduced surface expression of E-cadherin causes $\beta$-catenin to dissociate from the plasma membrane. When stabilized by active Wnt signaling or by mutations in the $\beta$-catenin phosphorylation/degradation pathway, $\beta$-catenin translocates to the nucleus where it modulates expression of genes involved in cell migration and invasion [233]. Additionally, soluble Ecadherin can disrupt adherens junctions and increase migration and invasion by activating EGFR signaling and upregulating several MMPs $[232,234]$. ADAM10 is a major protease for $\mathrm{N}$-cadherin shedding in vivo [235]. Increased $\mathrm{N}$-cadherin expression enhances the migration and invasiveness of cancer cells by acquiring an affinity for mesenchymal stroma cells [231, 236]. Surprisingly, ADAM10-mediated cleavage of Ncadherin enhances the migration of glioblastoma cells in vitro [199]. Tetraspanins have been recognized as positive and negative regulators of tumor cell migration [237]. As described above, tetraspanin CD9/TSPAN28 acts as adapter molecule of ADAM17 and contributes to ADAM17 surface activity. By this, CD9 indirectly contributes to shedding of adhesion molecules such as ALCAM, which then may contribute to its reported tumor suppressive function [237]. TSPANC8 family proteins (TSPAN5, TSPAN10, TSPAN14, TSPAN15, TSPAN17, and TSPAN33) differentially regulate ADAM10 compartmentalization and thereby selectively promote cleavage of $\mathrm{N}$-cadherin or CD44 which may represent critical steps in tumor cell migration $[55,238]$. In addition, tetraspanin TM4SF3/TSPAN8 promotes ADAM12 upregulation and by this esophageal carcinoma cell migration [239].

Similar to keratinocytes, EGFR ligand shedding and subsequent EGFR signaling are a key factor in tumor migration and invasion [240, 241]. For instance, ADAM17 enhances migration and invasion of breast cancer and glioblastoma stem cells by promoting EGFR signaling through shedding of several EGFR ligands $[214,215,242]$ and PI3K/AKT activation, for example, shown for TGF- $\alpha$ shedding in triplenegative breast cancer cell invasion [215] and EGFR activation in hypoxia-induced glioma cell invasion [243]. ADAM17 generates a transmembrane C-terminal fragment (tCTF) of syndecan-1, which is further processed by $\gamma$-secretase, resulting in a cytoplasmic C-terminal fragment (cCTF). Fulllength syndecan-1 and the tCTF mediated lung cancer cell invasion and metastasis, whereas the $\mathrm{CCTF}$ antagonized these functions $[174,175]$.

Overexpression of ADAM8 in pancreatic ductal adenocarcinoma cells increased their migratory and invasive capacities in vitro and in vivo by enhancing ERK1/2 signaling and MMP activity and the clustering of $\beta_{1}$ integrin [48]. Moreover, lung cancer cells express an alternatively spliced variant of ADAM8, termed Delta14, which increased lung metastasis to bone in vivo [244].

Hepatic stellate cells secrete an alternatively spliced soluble isoform of ADAM9 (ADAM9-S), which can interact with $\alpha_{6} \beta_{4}$ and $\alpha_{2} \beta_{1}$ integrins on colon carcinoma cells via its disintegrin domain. A similar interaction was also shown for $\alpha_{6} \beta_{1}$ integrin in prostate tumor cells [187]. Integrinbound ADAM9-S increases the invasive capacity of colon carcinoma cells by cleaving laminin and other ECM components in vitro [188]. Additionally, ADAM9-S increases breast cancer migration via its metalloproteinase activity, while the transmembrane form of ADAM9 (ADAM9-L) has the opposite effect on migration, which requires its disintegrin domain [185]. Furthermore, ADAM9 disintegrin domain mediates the interaction of fibroblasts and melanoma cells contributing to proteolytic activities required during invasion of melanoma cells [245].

ADAM10 can also generate soluble L1 cell adhesion molecule (L1CAM), which stimulates the migration of tumor cells through binding to the $\alpha_{v} \beta_{5}$ integrin [149]. Additionally, L1CAM shedding can take place either at the cell surface or in the endosomal and exosomal compartments, which is mediated by ADAM10 [196, 246]. The resulting soluble L1CAM enhances ERK phosphorylation and cell migration [246]. In glioma cells, upregulation of ADAM10 at the tumor edges was shown to result in increased soluble L1CAM, interacting with integrin receptors, activation of focal adhesion kinases, and focal complex turnover, all resulting in enhanced migration [197]. ALCAM is also upregulated on many tumors. ALCAM shedding from epithelial ovarian cancer (EOC) cells by ADAM17 interrupts adhesive functions, which is an essential step in EOC cell migration [247]. In oral squamous cell carcinoma, overexpression of ADAM10 associates with $\alpha_{v} \beta_{6}$ mediated invasiveness of the tumor cell [205]. In human nonsmall-cell lung cancer, overexpression of ADAM10 increased the migration and invasion potential of the tumor cells via the activation of the Notch 1 signaling pathway [200].

Highly metastatic tumors are associated with increased expression of ADAM12 [248]. Overexpression of ADAM12 increases migration and invasion of small cell lung cancer and head and neck squamous cell carcinoma cells [248, 249]. Further, adhesion states for migration and anchorage of melanoma cells are partly regulated by interactions of ADAM12 with $\alpha_{9} \beta_{1}$ [207]. As already described for ADAM9, ADAM12 exists in a transmembrane and in a soluble form. In particular, ADAM12-S was associated with breast cancer cell invasion in vitro and metastasis in vivo [206].

ADAM15 promotes the migration and invasion of nonsmall-cell lung cancer cells by increasing the expression of MMP9 and the conversion of pro-MMP9 to active form [210]. In contrast, ADAM15 suppresses vitronectin- and fibronectin-induced cell adhesion and migration in ovarian cancer cells by binding to the $\alpha_{v} \beta_{3}$ integrin via its RGD domain [212]. Interestingly, macrophage- and tumor-derived exosomes containing ADAM15 have a similar effect on cancer cell adhesion and migration via the same mechanism [250]. Similar to ADAM15, the proteolytically inactive ADAM23 can function as adhesion molecule by binding to the $\alpha_{v} \beta_{3}$ integrin and promoting cell-cell interactions and 
concomitantly modulating metastasis by reducing migration and adhesion to vitronectin [220]. Hyaluronic acid, another component of the ECM, is a ligand for the cellular adhesion molecule CD44. ADAM10 and ADAM17 regulate cell-ECM adhesion by shedding CD44, thereby stimulating CD44mediated migration of adenoma cells through Rac activation $[93,189]$.

6.2. Intra- and Extravasation of Cancer Cells. Upon reaching a blood or lymph vessel, invading cancer cells disrupt the endothelial junctions and cross the endothelium into the bloodstream. Surviving circulating cancer cells attach to endothelial cells in a similar manner as leukocytes (as discussed earlier), involving a wide range of ligands including transmembrane chemokines, selectins, integrins, cadherins, CD44, and immunoglobulin superfamily receptors, followed by transmigration.

ADAM8 stimulates endothelial transmigration of triplenegative breast cancer cells via $\beta 1$-activation in vitro and promotes tumor metastasis in vivo [183]. Eph receptor tyrosine kinases and their membrane-bound ligands, ephrins, are implicated in a variety of cellular responses, including repulsion, attraction, and migration, depending on the cell-type and receptor-ligand binding partners [251]. Eph receptor A1 and ephrin A1 complexes maintain cell-cell adhesion between endothelial cells, however enhancing ADAM12-mediated shedding of ephrin A1 by TGF- $\beta 1$ in primary tumors results in lung hyperpermeability that allows tumor cells to extravasate into the lungs [208]. Additionally, knockdown of ADAM15 in a prostate cancer cell line (PC-3) reduced adhesion to and transmigration through a monolayer of endothelial cells in vitro. In line, loss of ADAM15 in PC-3 cells injected in SCID mice led to an attenuated bone metastasis [209]. Cleavage of the transmembrane chemokine and adhesion molecule CXCL16 is predominantly mediated by ADAM10 [252]. Increased serum levels of shed CXCL16 have been correlated with high metastasis rate in ovarian cancer cells, which may reflect a prometastatic ADAM10 activity [191]. Moreover, soluble CXCL16 can mediate the attraction and adhesion of prostate cancer cells via $\alpha_{v} \beta_{3}$ integrin clustering [192]. On the other hand, high expression of CXCL16 but low ADAM10 expression, which presumably leads to less CXCL16 shedding and accumulation of transmembrane CXCL16, correlated with longer survival in renal cancer patients. Interestingly, transmembrane CXCL16 in renal cancer cells was found to act proadhesive but antimigratory [193].

\section{Conclusion and Outlook}

In summary, ADAMs 8, 9, 10, 12, 15 and 17 can contribute to cell migration by interfering with distinct steps of cell migration via a number of different effector molecules. This is true for inflammatory cells, various tissue cells, and cancer cells and involves proteolytic cleavage or nonproteolytic interactions of the proteases. Importantly, to promote cell migration, these actions must become efficient at the right time and the right place. For example, shedding of adhesion molecules on leukocytes before the migration process has started will result in less adhesiveness, but once an adherent leukocyte needs to resolve adhesion in order to move to its destination shedding of adhesion molecules may be required. Furthermore, when a tumor cell acquires a motile phenotype, ADAMs can resolve adhesion contacts to the ECM, thereby allowing dissemination of the tumor, but, on the other hand, when it comes to settlement of this motile cell to form a metastasis shedding of adhesion molecules can also prevent its attachment.

Studies with genetically altered mice indicate which ADAMs may hold a promigratory function in general. Deletion of ADAM10 in leukocytes reduces leukocyte recruitment in a murine model of acute lung inflammation [91]. ADAM10 deficient hepatocellular carcinoma showed less metastasis formation in vivo [203]. Transfer experiments also showed a promigratory role of ADAM8 on leukocytes (unpublished data) and on breast and pancreatic cancer cells $[48,183]$. Moreover, ADAM9 deficiency in lung cancer cells reduces metastasis in the brain [253]. However, deficiency of pathophysiologically important ADAM proteases does not necessarily reduce cell migration in general. For example, deficiency of ADAM17 in leukocytes clearly reduces inflammatory mediator production and reduces the response to bacterial sepsis [254], but the absence of this protease does not lead to diminished recruitment of inflammatory cells to inflammatory sites [88, 91, 255].

Thus, inhibition approaches for selected ADAM proteases on leukocytes or cancer cells are warranted. Inhibitor development is most advanced for ADAMs 8, 10, and 17 [32, 256]. In endotoxin-induced acute lung inflammation, treatment with a combined ADAM10/17 inhibitor was found to limit leukocyte recruitment [257]. In a murine model of allergic lung inflammation, ADAM10 inhibition could yield protective effects, which may be partly due to inhibition of leukocyte migration [258]. Interrupting ErbB receptor transactivation by a combined inhibitor of ADAM10 and ADAM17 reduced non-small-lung-cancer-cell formation, subcutaneous tumor growth, and breast cancer and fibroplasia [259, 260]. Furthermore, also ADAM8 inhibition via a neutralizing antibody or a cyclic peptide inhibitor led to a reduction of allergic lung inflammation, which is associated with a reduction of inflammatory cell infiltration [134, 261]. ADAM8 inhibition could also decrease metastasis of implanted pancreatic tumor cells [48]. ADAM12 inhibitory antibodies or genetically altered tissue inhibitor of metalloproteinases 2 (TIMP2) for specifically blocking ADAM12 or recombinant ADAM12 prodomain still need to be investigated in animal models of cancer cell migration [262, 263].

The present data indicate that inhibition of selected ADAMs may be of benefit in a situation of severe acute inflammation and/or cancer. However, as summarized in several other reviews, ADAMs also contribute to regenerative processes and additionally, for some less specific metalloproteinase inhibitors, hepatotoxicity has been reported [32, 256]. Therefore, it may be advisable to particularly target ADAMs on immune cells or cancer cells to prevent their undesired migration. The development of bivalent reagents binding to these target cells on the one hand and also specifically blocking ADAM proteases on the other hand may lead to a more specific treatment strategy. This approach may be of 
particular interest for breast cancers that critically depend on the generation of ErbB-family growth factors via ADAM10 or ADAM17 not only in terms of cell migration and metastasis but also in terms of cell proliferation and tumor growth.

\section{Competing Interests}

The authors declare that there are no competing interests regarding the publication of this paper.

\section{Authors' Contributions}

D. Dreymueller and K. Theodorou share first authorship; M. Donners and A. Ludwig share senior authorship.

\section{Acknowledgments}

The project was funded by grants from the DFG (DR1013/1 for D. Dreymueller and Lu869/5-1-2 for A. Ludwig) and the Netherlands Heart Foundation (2012T079 for M. Donners).

\section{References}

[1] K. F. Swaney, C.-H. Huang, and P. N. Devreotes, "Eukaryotic chemotaxis: a network of signaling pathways controls motility, directional sensing, and polarity," Annual Review of Biophysics, vol. 39, no. 1, pp. 265-289, 2010.

[2] C. B. Gurniak, E. Perlas, and W. Witke, "The actin depolymerizing factor $\mathrm{n}$-cofilin is essential for neural tube morphogenesis and neural crest cell migration," Developmental Biology, vol. 278, no. 1, pp. 231-241, 2005.

[3] H. T. Petrie, "Cell migration and the control of post-natal T-cell lymphopoiesis in the thymus," Nature Reviews Immunology, vol. 3, no. 11, pp. 859-866, 2003.

[4] S. Kurosaka and A. Kashina, "Cell biology of embryonic migration," Birth Defects Research Part C-Embryo Today: Reviews, vol. 84, no. 2, pp. 102-122, 2008.

[5] S. F. Louis and P. Zahradka, "Vascular smooth muscle cell motility: from migration to invasion," Experimental and Clinical Cardiology, vol. 15, no. 4, pp. e75-e85, 2010.

[6] M. Vicente-Manzanares and A. R. Horwitz, "Cell migration: an overview," Methods in Molecular Biology, vol. 769, pp. 1-24, 2011.

[7] F. van Zijl, G. Krupitza, and W. Mikulits, "Initial steps of metastasis: cell invasion and endothelial transmigration," Mutation Research/Reviews in Mutation Research, vol. 728, no. 1-2, pp. 2334, 2011.

[8] S. Garrido-Urbani, P. F. Bradfield, B. P.-L. Lee, and B. A. Imhof, "Vascular and epithelial junctions: a barrier for leucocyte migration," Biochemical Society Transactions, vol. 36, no. 2, pp. 203-211, 2008.

[9] S. G. Ricoult, T. E. Kennedy, and D. Juncker, "Substrate-bound protein gradients to study haptotaxis," Frontiers in Bioengineering and Biotechnology, vol. 3, article 40, 2015.

[10] P. Roca-Cusachs, R. Sunyer, and X. Trepat, "Mechanical guidance of cell migration: lessons from chemotaxis," Current Opinion in Cell Biology, vol. 25, pp. 543-549, 2013.

[11] S. V. Plotnikov, A. M. Pasapera, B. Sabass, and C. M. Waterman, "Force fluctuations within focal adhesions mediate ECMrigidity sensing to guide directed cell migration," Cell, vol. 151, no. 7, pp. 1513-1527, 2012.
[12] P. J. M. Van Haastert and P. N. Devreotes, "Chemotaxis: signalling the way forward," Nature Reviews Molecular Cell Biology, vol. 5, no. 8, pp. 626-634, 2004.

[13] P. Hotulainen and P. Lappalainen, "Stress fibers are generated by two distinct actin assembly mechanisms in motile cells," Journal of Cell Biology, vol. 173, no. 3, pp. 383-394, 2006.

[14] J. D. Humphries, A. Byron, and M. J. Humphries, "Integrin ligands at a glance," Journal of Cell Science, vol. 119, no. 19, pp. 3901-3903, 2006.

[15] M. Gimona, R. Buccione, S. A. Courtneidge, and S. Linder, "Assembly and biological role of podosomes and invadopodia," Current Opinion in Cell Biology, vol. 20, no. 2, pp. 235-241, 2008.

[16] K. Wolf and P. Friedl, "Mapping proteolytic cancer cellextracellular matrix interfaces," Clinical and Experimental Metastasis, vol. 26, no. 4, pp. 289-298, 2009.

[17] T. Maretzky, A. Evers, W. Zhou et al., "Migration of growth factor-stimulated epithelial and endothelial cells depends on EGFR transactivation by ADAM17," Nature Communications, vol. 2, no. 1, article 229, 2011.

[18] H. Ohtsu, P. J. Dempsey, and S. Eguchi, "ADAMs as mediators of EGF receptor transactivation by G protein-coupled receptors," American Journal of Physiology-Cell Physiology, vol. 291, no. 1, pp. C1-C10, 2006.

[19] J. J. Peschon, J. L. Slack, P. Reddy et al., "An essential role for ectodomain shedding in mammalian development," Science, vol. 282, no. 5392, pp. 1281-1284, 1998.

[20] K. J. Garton, P. J. Gough, J. Philalay et al., "Stimulated shedding of vascular cell adhesion molecule 1 (VCAM-1) is mediated by tumor necrosis factor- $\alpha$-converting enzyme (ADAM 17)," Journal of Biological Chemistry, vol. 278, no. 39, pp. 3745937464, 2003.

[21] N. L. Tsakadze, S. D. Sithu, U. Sen, W. R. English, G. Murphy, and S. E. D'Souza, "Tumor necrosis factor- $\alpha$-converting enzyme (TACE/ADAM-17) mediates the ectodomain cleavage of Intercellular Adhesion Molecule-1 (ICAM-1)," Journal of Biological Chemistry, vol. 281, no. 6, pp. 3157-3164, 2006.

[22] C. Hundhausen, D. Misztela, T. A. Berkhout et al., "The disintegrin-like metalloproteinase ADAM10 is involved in constitutive cleavage of CX3CL1 (fractalkine) and regulates CX3CL1-mediated cell-cell adhesion," Blood, vol. 102, no. 4, pp. 1186-1195, 2003.

[23] S. Abel, C. Hundhausen, R. Mentlein et al., "The transmembrane CXC-chemokine ligand 16 is induced by IFN- $\gamma$ and TNF$\alpha$ and shed by the activity of the disintegrin-like metalloproteinase ADAM10," The Journal of Immunology, vol. 172, no. 10, pp. 6362-6372, 2004.

[24] N. Giebeler and P. Zigrino, "A disintegrin and metalloprotease (ADAM): historical overview of their functions," Toxins, vol. 8, no. 4, article 122, 2016.

[25] D. F. Seals and S. A. Courtneidge, "The ADAMs family of metalloproteases: multidomain proteins with multiple functions," Genes and Development, vol. 17, no. 1, pp. 7-30, 2003.

[26] S. Takeda, "ADAM and ADAMTS family proteins and snake venom metalloproteinases: a structural overview," Toxins, vol. 8 , no. 5, article 155, 2016.

[27] S. Düsterhöft, S. Jung, C.-W. Hung et al., "Membrane-proximal domain of a disintegrin and metalloprotease-17 represents the putative molecular switch of its shedding activity operated by protein-disulfide isomerase," Journal of the American Chemical Society, vol. 135, no. 15, pp. 5776-5781, 2013. 
[28] S. Takeda, "Three-dimensional domain architecture of the ADAM family proteinases," Seminars in Cell and Developmental Biology, vol. 20, no. 2, pp. 146-152, 2009.

[29] P. W. Janes, N. Saha, W. A. Barton et al., "Adam meets Eph: an ADAM substrate recognition module acts as a molecular switch for ephrin cleavage in trans," Cell, vol. 123, no. 2, pp. 291-304, 2005.

[30] C. Andreini, L. Banci, I. Bertini, S. Elmi, and A. Rosato, "Comparative analysis of the ADAM and ADAMTS families," Journal of Proteome Research, vol. 4, no. 3, pp. 881-888, 2005.

[31] A. Zolkiewska, "ADAM proteases: ligand processing and modulation of the Notch pathway," Cellular and Molecular Life Sciences, vol. 65, no. 13, pp. 2056-2068, 2008.

[32] D. Dreymueller, S. Uhlig, and A. Ludwig, "Adam-family metalloproteinases in lung inflammation: potential therapeutic targets," American Journal of Physiology-Lung Cellular and Molecular Physiology, vol. 308, no. 4, pp. L325-L343, 2015.

[33] R. A. Black, J. R. Doedens, R. Mahimkar et al., "Substrate specificity and inducibility of TACE (tumour necrosis factor $\alpha$-converting enzyme) revisited: the Ala-Val preference, and induced intrinsic activity," Biochemical Society Symposium, no. 70, pp. 39-52, 2003.

[34] R. Stawikowska, M. Cudic, M. Giulianotti, R. A. Houghten, G. B. Fields, and D. Minond, "Activity of ADAM17 (a disintegrin and metalloprotease 17) is regulated by its noncatalytic domains and secondary structure of its substrates," Journal of Biological Chemistry, vol. 288, pp. 22871-22879, 2013.

[35] C. I. Caescu, G. R. Jeschke, and B. E. Turk, "Active-site determinants of substrate recognition by the metalloproteinases TACE and ADAM10," Biochemical Journal, vol. 424, no. 1, pp. 79-88, 2009.

[36] S. Düsterhöft, M. Michalek, F. Kordowski et al., "Extracellular juxtamembrane segment of ADAM17 interacts with membranes and is essential for its shedding activity," Biochemistry, vol. 54, no. 38, pp. 5791-5801, 2015.

[37] S. Düsterhöft, K. Höbel, M. Oldefest et al., "A disintegrin and metalloprotease 17 dynamic interaction sequence, the sweet tooth for the human interleukin 6 receptor," The Journal of Biological Chemistry, vol. 289, no. 23, pp. 16336-16348, 2014.

[38] T. Maretzky, D. R. McIlwain, P. D. A. Issuree et al., "iRhom 2 controls the substrate selectivity of stimulated ADAM17-dependent ectodomain shedding," Proceedings of the National Academy of Sciences of the United States of America, vol. 110, no. 28, pp. 11433-11438, 2013.

[39] M. Dang, N. Armbruster, M. A. Miller et al., "Regulated ADAM17-dependent EGF family ligand release by substrateselecting signaling pathways," Proceedings of the National Academy of Sciences of the United States of America, vol. 110, no. 24, pp. 9776-9781, 2013.

[40] A. Sommer, F. Kordowski, J. Büch et al., "Phosphatidylserine exposure is required for ADAM17 sheddase function," Nature Communications, vol. 7, Article ID 11523, 2016.

[41] K. Reiss, I. Cornelsen, M. Husmann, G. Gimpl, and S. Bhakdi, "Unsaturated fatty acids drive disintegrin and metalloproteinase (ADAM)-dependent cell adhesion, proliferation, and migration by modulating membrane fluidity," The Journal of Biological Chemistry, vol. 286, no. 30, pp. 26931-26942, 2011.

[42] M. J. Duffy, M. Mullooly, N. O'Donovan et al., “The ADAMs family of proteases: new biomarkers and therapeutic targets for cancer?" Clinical Proteomics, vol. 8, article 9, 2011.

[43] D. Dreymueller, J. Pruessmeyer, E. Groth, and A. Ludwig, "The role of ADAM-mediated shedding in vascular biology,"
European Journal of Cell Biology, vol. 91, no. 6-7, pp. 472-485, 2012.

[44] P. E. Gonzales, A. Solomon, A. B. Miller, M. A. Leesnitzer, I. Sagis, and M. E. Milla, "Inhibition of the tumor necrosis factor$\alpha$-converting enzyme by its pro domain," Journal of Biological Chemistry, vol. 279, no. 30, pp. 31638-31645, 2004.

[45] E. Tellier, M. Canault, L. Rebsomen et al., "The shedding activity of ADAM17 is sequestered in lipid rafts," Experimental Cell Research, vol. 312, no. 20, pp. 3969-3980, 2006.

[46] P. D. A. Issuree, T. Maretzky, D. R. McIlwain et al., "iRHOM2 is a critical pathogenic mediator of inflammatory arthritis," Journal of Clinical Investigation, vol. 123, no. 2, pp. 928-932, 2013.

[47] M. Gómez-Gaviro, M. Domínguez-Luis, J. Canchado et al., "Expression and regulation of the metalloproteinase ADAM8 during human neutrophil pathophysiological activation and its catalytic activity on L-selectin shedding," The Journal of Immunology, vol. 178, no. 12, pp. 8053-8063, 2007.

[48] U. Schlomann, G. Koller, C. Conrad et al., "ADAM8 as a drug target in pancreatic cancer," Nature Communications, vol. 6, article 6175, 2015.

[49] U. Schlomann, D. Wildeboer, A. Webster et al., "The metalloprotease disintegrin ADAM8. Processing by autocatalysis is required for proteolytic activity and cell adhesion," Journal of Biological Chemistry, vol. 277, no. 50, pp. 48210-48219, 2002.

[50] S. H. Willems, C. J. Tape, P. L. Stanley et al., "Thiol isomerases negatively regulate the cellular shedding activity of ADAM17," Biochemical Journal, vol. 428, no. 3, pp. 439-450, 2010.

[51] S. M. Le Gall, T. Maretzky, P. D. A. Issuree et al., "ADAM17 is regulated by a rapid and reversible mechanism that controls access to its catalytic site," Journal of Cell Science, vol. 123, no. 22, pp. 3913-3922, 2010.

[52] C. Adrain, M. Zettl, Y. Christova, N. Taylor, and M. Freeman, "Tumor necrosis factor signaling requires iRhom 2 to promote trafficking and activation of TACE," Science, vol. 335, no. 6065, pp. 225-228, 2012.

[53] Y. Christova, C. Adrain, P. Bambrough, A. Ibrahim, and M. Freeman, "Mammalian iRhoms have distinct physiological functions including an essential role in TACE regulation," EMBO Reports, vol. 14, no. 10, pp. 884-890, 2013.

[54] C. Arduise, T. Abache, L. Li et al., "Tetraspanins regulate ADAM10-mediated cleavage of TNF- $\alpha$ and epidermal growth factor," The Journal of Immunology, vol. 181, no. 10, pp. 7002 7013, 2008

[55] E. J. Haining, J. Yang, R. L. Bailey et al., “The TspanC8 subgroup of tetraspanins interacts with a disintegrin and metalloprotease 10 (ADAM10) and regulates its maturation and cell surface expression," Journal of Biological Chemistry, vol. 287, no. 47, pp. 39753-39765, 2012.

[56] M. D. Gutiérrez-López, A. Gilsanz, M. Yàñez-Mó et al., "The sheddase activity of ADAM17/TACE is regulated by the tetraspanin CD9," Cellular and Molecular Life Sciences, vol. 68, no. 19, pp. 3275-3292, 2011.

[57] A. Amour, C. G. Knight, A. Webster et al., "The in vitro activity of ADAM-10 is inhibited by TIMP-1 and TIMP-3," FEBS Letters, vol. 473, no. 3, pp. 275-279, 2000.

[58] A. Amour, P. M. Slocombe, A. Webster et al., "TNF- $\alpha$ converting enzyme (TACE) is inhibited by TIMP-3," FEBS Letters, vol. 435, no. 1, pp. 39-44, 1998.

[59] B. Schulz, J. Pruessmeyer, T. Maretzky et al., "ADAMIO regulates endothelial permeability and T-cell transmigration by proteolysis of vascular endothelial cadherin," Circulation Research, vol. 102, no. 10, pp. 1192-1201, 2008. 
[60] M. M. P. C. Donners, I. M. J. Wolfs, S. Olieslagers et al., "A Disintegrin and Metalloprotease 10 is a novel mediator of vascular endothelial growth factor-induced endothelial cell function in angiogenesis and is associated with atherosclerosis," Arteriosclerosis, Thrombosis, and Vascular Biology, vol. 30, no. 11, pp. 2188-2195, 2010.

[61] T. Maretzky, K. Reiss, A. Ludwig et al., "ADAM10 mediates Ecadherin shedding and regulates epithelial cell-cell adhesion, migration, and $\beta$-catenin translocation," Proceedings of the National Academy of Sciences of the United States of America, vol. 102, no. 26, pp. 9182-9187, 2005.

[62] R. R. Koenen, J. Pruessmeyer, O. Soehnlein et al., "Regulated release and functional modulation of junctional adhesion molecule A by disintegrin metalloproteinases," Blood, vol. 113, no. 19, pp. 4799-4809, 2009.

[63] A. Woodfin, C. A. Reichel, A. Khandoga et al., "JAM-A mediates neutrophil transmigration in a stimulus-specific manner in vivo: evidence for sequential roles for JAM-A and PECAM-1 in neutrophil transmigration," Blood, vol. 110, no. 6, pp. 1848-1856, 2007.

[64] F. Scholz, A. Schulte, F. Adamski et al., "Constitutive expression and regulated release of the transmembrane chemokine CXCL16 in human and murine skin," Journal of Investigative Dermatology, vol. 127, no. 6, pp. 1444-1455, 2007.

[65] M. G. Andrzejewski, A. Koelsch, T. Kogel, D. Dreymueller, N. Schwarz, and A. Ludwig, "Distinct role of the intracellular Cterminus for subcellular expression, shedding and function of the murine transmembrane chemokine CX3CL1," Biochemical and Biophysical Research Communications, vol. 395, no. 2, pp. 178-184, 2010.

[66] F. Geissmann, T. O. Cameron, S. Sidobre et al., "Intravascular immune surveillance by $\mathrm{CXCR}^{+}{ }^{+} \mathrm{NKT}$ cells patrolling liver sinusoids," PLoS Biology, vol. 3, no. 4, p. el13, 2005.

[67] N. Schwarz, J. Pruessmeyer, F. M. Hess et al., "Requirements for leukocyte transmigration via the transmembrane chemokine CX3CL1," Cellular and Molecular Life Sciences, vol. 67, no. 24, pp. 4233-4248, 2010.

[68] C. Agostini, A. Cabrelle, F. Calabrese et al., "Role for CXCR6 and its ligand CXCL16 in the pathogenesis of T-cell alveolitis in sarcoidosis," American Journal of Respiratory and Critical Care Medicine, vol. 172, no. 10, pp. 1290-1298, 2005.

[69] D. Dreymueller, A. Goetzenich, C. Emontzpohl, J. Soppert, A. Ludwig, and C. Stoppe, "The perioperative time course and clinical significance of the chemokine CXCL16 in patients undergoing cardiac surgery," Journal of Cellular and Molecular Medicine, vol. 20, no. 1, pp. 104-115, 2016.

[70] K. Hase, T. Murakami, H. Takatsu et al., "The membrane-bound chemokine CXCL16 expressed on follicle-associated epithelium and M cells mediates lympho-epithelial interaction in GALT," Journal of Immunology, vol. 176, no. 1, pp. 43-51, 2006.

[71] K. Hattermann, A. Ludwig, V. Gieselmann, J. Held-Feindt, and R. Mentlein, "The chemokine CXCL16 induces migration and invasion of glial precursor cells via its receptor CXCR6," Molecular and Cellular Neuroscience, vol. 39, no. 1, pp. 133-141, 2008.

[72] A. Wehr, C. Baeck, F. Ulmer et al., "Pharmacological inhibition of the chemokine CXCL16 diminishes liver macrophage infiltration and steatohepatitis in chronic hepatic injury," PLoS ONE, vol. 9, no. 11, Article ID el12327, 2014.

[73] T. Isozaki, S. Ishii, S. Nishimi et al., "A disintegrin and metalloprotease-10 is correlated with disease activity and mediates monocyte migration and adhesion in rheumatoid arthritis," Translational Research, vol. 166, no. 3, pp. 244-253, 2015.

[74] B. A. Jones, M. Beamer, and S. Ahmed, "Fractalkine/CX3CL1: a potential new target for inflammatory diseases," Molecular Interventions, vol. 10, no. 5, pp. 263-270, 2010.

[75] C. Herzog, R. S. Haun, A. Ludwig, S. V. Shah, and G. P. Kaushal, "ADAM10 is the major sheddase responsible for the release of membrane-Associated meprin A," Journal of Biological Chemistry, vol. 289, no. 19, pp. 13308-13322, 2014.

[76] T. Jefferson, U. auf dem Keller, C. Bellac et al., "The substrate degradome of meprin metalloproteases reveals an unexpected proteolytic link between meprin $\beta$ and ADAM10," Cellular and Molecular Life Sciences, vol. 70, no. 2, pp. 309-333, 2013.

[77] J. Prox, P. Arnold, and C. Becker-Pauly, "Meprin $\alpha$ and meprin $\beta$ : procollagen proteinases in health and disease," Matrix Biology, vol. 44-46, pp. 7-13, 2015.

[78] M. Huguenin, E. J. Müller, S. Trachsel-Rösmann et al., “The metalloprotease meprin $\beta$ processes E-cadherin and weakens intercellular adhesion," PLoS ONE, vol. 3, no. 5, Article ID e2153, 2008.

[79] D. Frommhold, A. Kamphues, I. Hepper et al., "RAGE and ICAM-1 cooperate in mediating leukocyte recruitment during acute inflammation in vivo," Blood, vol. 116, no. 5, pp. 841-849, 2010.

[80] K. Zen, C. X.-J. Chen, Y.-T. Chen, R. Wilton, and Y. Liu, "Receptor for advanced glycation endproducts mediates neutrophil migration across intestinal epithelium," Journal of Immunology, vol. 178, no. 4, pp. 2483-2490, 2007.

[81] K. Kierdorf and G. Fritz, "RAGE regulation and signaling in inflammation and beyond," Journal of Leukocyte Biology, vol. 94, no. 1, pp. 55-68, 2013.

[82] A. Braley, T. Kwak, J. Jules, E. Harja, R. Landgraf, and B. I. Hudson, "Regulation of receptor for advanced glycation end products (rage) ectodomain shedding and its role in cell function," Journal of Biological Chemistry, vol. 291, no. 23, pp. 12057-12073, 2016.

[83] A. Masedunskas, J. A. King, F. Tan et al., "Activated leukocyte cell adhesion molecule is a component of the endothelial junction involved in transendothelial monocyte migration," FEBS Letters, vol. 580, no. 11, pp. 2637-2645, 2006.

[84] A. Gilsanz, L. Sánchez-Martín, M. D. Gutiérrez-López et al., "ALCAM/CD166 adhesive function is regulated by the tetraspanin CD9," Cellular and Molecular Life Sciences, vol. 70, no. 3, pp. 475-493, 2013.

[85] R. Cayrol, K. Wosik, J. L. Berard et al., "Activated leukocyte cell adhesion molecule promotes leukocyte trafficking into the central nervous system," Nature Immunology, vol. 9, no. 2, pp. 137-145, 2008.

[86] Y. Tsubota, J. M. Frey, P. W. L. Tai, R. E. Welikson, and E. W. Raines, "Monocyte ADAM17 promotes diapedesis during transendothelial migration: identification of steps and substrates targeted by metalloproteinases," Journal of Immunology, vol. 190, no. 8, pp. 4236-4244, 2013.

[87] U. Schaff, P. E. Mattila, S. I. Simon, and B. Walcheck, "Neutrophil adhesion to E-selectin under shear promotes the redistribution and co-clustering of ADAM17 and its proteolytic substrate L-selectin," Journal of Leukocyte Biology, vol. 83, no. 1, pp. 99-105, 2008.

[88] J. Tang, A. Zarbock, I. Gomez et al., "Adam17-dependent shedding limits early neutrophil influx but does not alter early monocyte recruitment to inflammatory sites," Blood, vol. 118, no. 3, pp. 786-794, 2011. 
[89] H. K. Mishra, C. Long, N. S. Bahaie, and B. Walcheck, "Regulation of CXCR2 expression and function by a disintegrin and metalloprotease-17 (ADAM17)," Journal of Leukocyte Biology, vol. 97, no. 3, pp. 447-454, 2015.

[90] U. Sahin, G. Weskamp, K. Kelly et al., "Distinct roles for ADAM10 and ADAM17 in ectodomain shedding of six EGFR ligands," Journal of Cell Biology, vol. 164, no. 5, pp. 769-779, 2004.

[91] J. Pruessmeyer, F. M. Hess, H. Alert et al., "Leukocytes require ADAM10 but not ADAM17 for their migration and inflammatory recruitment into the alveolar space," Blood, vol. 123, no. 26, pp. 4077-4088, 2014.

[92] A. Holzer, K. Watzinger, and M. Kähler, "Activation of the $\mathrm{NOTCH}$ signaling pathway stimulates migration of human Blymphocytes," The European Respiratory Journal, vol. 46, p. PA389, 2015.

[93] O. Nagano, D. Murakami, D. Hartmann et al., "Cell-matrix interaction via CD44 is independently regulated by different metalloproteinases activated in response to extracellular $\mathrm{Ca}^{2+}$ influx and PKC activation," The Journal of Cell Biology, vol. 165, no. 6, pp. 893-902, 2004.

[94] B. McDonald and P. Kubes, "Interactions between CD44 and hyaluronan in leukocyte trafficking," Frontiers in Immunology, vol. 6, Article ID 00068, 2015.

[95] T. Yoshimura, W. Matsuyama, and H. Kamohara, "Discoidin domain receptor 1: a new class of receptor regulating leukocytecollagen interaction," Immunologic Research, vol. 31, no. 3, pp. 219-229, 2005.

[96] A. Jalili, N. Shirvaikar, L. A. Marquez-Curtis, A. R. Turner, and A. Janowska-Wieczorek, "The HGF/c-Met axis synergizes with G-CSF in the mobilization of hematopoietic stem/progenitor cells," Stem Cells and Development, vol. 19, no. 8, pp. 1143-1151, 2010.

[97] I. Dekaris, S.-N. Zhu, and M. R. Dana, "TNF- $\alpha$ regulates corneal Langerhans cell migration," Journal of Immunology, vol. 162, no. 7, pp. 4235-4239, 1999.

[98] M. Weissenbach, T. Clahsen, C. Weber et al., "Interleukin-6 is a direct mediator of T cell migration," European Journal of Immunology, vol. 34, no. 10, pp. 2895-2906, 2004.

[99] J. H. Bell, A. H. Herrera, Y. Li, and B. Walcheck, "Role of ADAM17 in the ectodomain shedding of TNF- $\alpha$ and its receptors by neutrophils and macrophages," Journal of Leukocyte Biology, vol. 82, no. 1, pp. 173-176, 2007.

[100] S. J. Levine, "Mechanisms of soluble cytokine receptor generation," The Journal of Immunology, vol. 173, no. 9, pp. 5343-5348, 2004.

[101] M. Domínguez-Luis, A. Lamana, J. Vazquez et al., “The metalloprotease ADAM8 is associated with and regulates the function of the adhesion receptor PSGL-1 through ERM proteins," European Journal of Immunology, vol. 41, no. 12, pp. 3436-3442, 2011.

[102] A. Zarbock and J. Rossaint, "Regulating inflammation: ADAM8-a new player in the game," European Journal of Immunology, vol. 41, no. 12, pp. 3419-3422, 2011.

[103] K. M. Veerman, D. A. Carlow, I. Shanina, J. J. Priatel, M. S. Horwitz, and H. J. Ziltener, "PSGL-1 regulates the migration and proliferation of $\mathrm{CD}^{+} \mathrm{T}$ cells under homeostatic conditions," Journal of Immunology, vol. 188, no. 4, pp. 1638-1646, 2012.

[104] S. F. Lichtenthaler, D.-I. Dominguez, G. G. Westmeyer et al., "The cell adhesion protein P-selectin glycoprotein ligand-1 is a substrate for the aspartyl protease BACE1," The Journal of Biological Chemistry, vol. 278, no. 49, pp. 48713-48719, 2003.
[105] S. Naus, M.-R. Blanchet, K. Gossens et al., "The metalloprotease-disintegrin ADAM8 is essential for the development of experimental asthma," American Journal of Respiratory and Critical Care Medicine, vol. 181, no. 12, pp. 1318-1328, 2010.

[106] M. D. Knolle, T. Nakajima, A. Hergrueter et al., "Adam8 limits the development of allergic airway inflammation in mice," The Journal of Immunology, vol. 190, no. 12, pp. 6434-6449, 2013.

[107] C. Sun, M. H. Wu, E. S. Lee, and S. Y. Yuan, "A disintegrin and metalloproteinase 15 contributes to atherosclerosis by mediating endothelial barrier dysfunction via src family kinase activity," Arteriosclerosis, Thrombosis, and Vascular Biology, vol. 32, no. 10, pp. 2444-2451, 2012.

[108] Q. Chen, L.-H. Meng, C.-H. Zhu, L.-P. Lin, H. Lu, and J. Ding, "ADAM15 suppresses cell motility by driving integrin $\alpha 5 \beta 1$ cell surface expression via Erk inactivation," The International Journal of Biochemistry \& Cell Biology, vol. 40, no. 10, pp. 2164$2173,2008$.

[109] C. Sun, R. S. Beard, D. L. Mclean et al., "ADAM15 deficiency attenuates pulmonary hyperpermeability and acute lung injury in lipopolysaccharide-treated mice," American Journal of Physiology-Lung Cellular and Molecular Physiology, vol. 304, no. 3, pp. L135-L142, 2013.

[110] L. C. Bridges, D. Sheppard, and R. D. Bowditch, "ADAM disintegrin-like domain recognition by the lymphocyte integrins $\alpha 4 \beta 1$ and $\alpha 4 \beta 7$," Biochemical Journal, vol. 387, no. 1, pp. 101-108, 2005.

[111] R. S. Amendola, A. C. B. M. Martin, H. S. Selistre-De-Araújo, H. A. Paula-Neto, R. Saldanha-Gama, and C. Barja-Fidalgo, "ADAM9 disintegrin domain activates human neutrophils through an autocrine circuit involving integrins and cxcr2," Journal of Leukocyte Biology, vol. 97, no. 5, pp. 951-962, 2015.

[112] E. P. C. van der Vorst, A. A. Keijbeck, M. P. J. de Winther, and M. M. P. C. Donners, "A disintegrin and metalloproteases: molecular scissors in angiogenesis, inflammation and atherosclerosis," Atherosclerosis, vol. 224, no. 2, pp. 302-308, 2012.

[113] A. Bar-Or, R. K. Nuttall, M. Duddy et al., "Analyses of all matrix metalloproteinase members in leukocytes emphasize monocytes as major inflammatory mediators in multiple sclerosis," Brain, vol. 126, no. 12, pp. 2738-2749, 2003.

[114] B. C. Kieseier, H. Pischel, E. Neuen-Jacob, W. W. Tourtellotte, and H.-P. Hartung, "ADAM-10 and ADAM-17 in the inflamed human CNS," Glia, vol. 42, no. 4, pp. 398-405, 2003.

[115] T. Seifert, B. C. Kieseier, S. Ropele et al., "TACE mRNA expression in peripheral mononuclear cells precedes new lesions on MRI in multiple sclerosis," Multiple Sclerosis, vol. 8, no. 6, pp. 447-451, 2002.

[116] J. Plumb, S. McQuaid, A. K. Cross et al., "Upregulation of ADAM-17 expression in active lesions in multiple sclerosis," Multiple Sclerosis, vol. 12, no. 4, pp. 375-385, 2006.

[117] I. A. Scarisbrick, “The multiple sclerosis degradome: enzymatic cascades in development and progression of central nervous system inflammatory disease," Current Topics in Microbiology and Immunology, vol. 318, pp. 133-175, 2008.

[118] S. Ohta, M. Harigai, M. Tanaka et al., "Tumor necrosis factor- $\alpha$ (TNF- $\alpha$ ) converting enzyme contributes to production of TNF$\alpha$ in synovial tissues from patients with rheumatoid arthritis," Journal of Rheumatology, vol. 28, no. 8, pp. 1756-1763, 2001.

[119] B. B. Böhm, T. Aigner, C. P. Blobel, J. R. Kalden, and H. Burkhardt, "Highly enhanced expression of the disintegrin metalloproteinase MDC15 (metargidin) in rheumatoid synovial tissue," Arthritis and Rheumatism, vol. 44, no. 9, pp. 2046-2054, 2001. 
[120] D. Li, Z. Xiao, G. Wang, and X. Song, "Knockdown of ADAM10 inhibits migration and invasion of fibroblast-like synoviocytes in rheumatoid arthritis," Molecular Medicine Reports, vol. 12, no. 4, pp. 5517-5523, 2015.

[121] T. Isozaki, B. J. Rabquer, J. H. Ruth, G. K. Haines III, and A. E. Koch, "ADAM-10 is overexpressed in rheumatoid arthritis synovial tissue and mediates angiogenesis," Arthritis and Rheumatism, vol. 65, no. 1, pp. 98-108, 2013.

[122] C. Garbers, N. Jänner, A. Chalaris et al., "Species specificity of ADAM10 and ADAM17 proteins in interleukin-6 (IL-6) transsignaling and novel role of ADAM10 in inducible IL-6 receptor shedding," The Journal of Biological Chemistry, vol. 286, no. 17, pp. 14804-14811, 2011.

[123] T. Isozaki, S. Nishimi, A. Nishimi et al., "A disintegrin and metalloproteinase (ADAM)-10 as a predictive factor for tocilizumab effectiveness in rheumatoid arthritis," Modern Rheumatology, 2016.

[124] J. Gao, W. Zheng, L. Wang, and B. Song, "A disintegrin and metallproteinase 15 knockout decreases migration of fibroblastlike synoviocytes and inflammation in rheumatoid arthritis," Molecular Medicine Reports, vol. 11, no. 6, pp. 4389-4396, 2015.

[125] K. Komiya, H. Enomoto, I. Inoki et al., "Expression of ADAM15 in rheumatoid synovium: up-regulation by vascular endothelial growth factor and possible implications for angiogenesis," Arthritis Research \& Therapy, vol. 7, no. 6, pp. R1158-R1173, 2005.

[126] J. Pelisek, J. Pongratz, L. Deutsch, C. Reeps, T. Stadlbauer, and H.-H. Eckstein, "Expression and cellular localization of metalloproteases ADAMs in high graded carotid artery lesions," Scandinavian Journal of Clinical and Laboratory Investigation, vol. 72, no. 8, pp. 648-656, 2012.

[127] J. W. Holloway, R. C. Laxton, M. J. Rose-Zerilli et al., "ADAM33 expression in atherosclerotic lesions and relationship of ADAM33 gene variation with atherosclerosis," Atherosclerosis, vol. 211, no. 1, pp. 224-230, 2010.

[128] N. Oksala, M. Levula, N. Airla et al., "ADAM-9, ADAM-15, and ADAM-17 are upregulated in macrophages in advanced human atherosclerotic plaques in aorta and carotid and femoral arteriesTampere vascular study," Annals of Medicine, vol. 41, no. 4, pp. 279-290, 2009.

[129] M. Levula, N. Airla, N. Oksala et al., "ADAM8 and its single nucleotide polymorphism $2662 \mathrm{~T} / \mathrm{G}$ are associated with advanced atherosclerosis and fatal myocardial infarction: tampere vascular study," Annals of Medicine, vol. 41, no. 7, pp. 497507, 2009.

[130] E. P. C. van der Vorst, M. Jeurissen, I. M. J. Wolfs et al., "Myeloid a disintegrin and metalloproteinase domain 10 deficiency modulates atherosclerotic plaque composition by shifting the balance from inflammation toward fibrosis," The American Journal of Pathology, vol. 185, no. 4, pp. 1145-1155, 2015.

[131] Q. Xiao, F. Zhang, G. Grassia et al., "Matrix metalloproteinase8 promotes vascular smooth muscle cell proliferation and neointima formation," Arteriosclerosis, Thrombosis, and Vascular Biology, vol. 34, no. 1, pp. 90-98, 2014.

[132] T. J. Shaw and P. Martin, "Wound repair at a glance," Journal of Cell Science, vol. 122, no. 18, pp. 3209-3213, 2009.

[133] J. Huang, L. C. Bridges, and J. M. White, "Selective modulation of integrin-mediated cell migration by distinct ADAM family members," Molecular Biology of the Cell, vol. 16, no. 10, pp. 49824991, 2005.

[134] G. Paulissen, N. Rocks, M. M. Guéders et al., "ADAM8 , a metalloproteinase, drives acute allergen-induced airway inflammation," European Journal of Immunology, vol. 41, no. 2, pp. 380-391, 2011.

[135] T. W. Faber, N. A. Pullen, J. F. A. Fernando et al., "ADAM10 is required for SCF-induced mast cell migration," Cellular Immunology, vol. 290, no. 1, pp. 80-88, 2014.

[136] C. Long, M. R. Hosseinkhani, Y. Wang, P. Sriramarao, and B. Walcheck, "ADAM17 activation in circulating neutrophils following bacterial challenge impairs their recruitment," Journal of Leukocyte Biology, vol. 92, no. 3, pp. 667-672, 2012.

[137] A. P. Gregory, C. A. Dendrou, K. E. Attfield et al., “TNF receptor 1 genetic risk mirrors outcome of anti-TNF therapy in multiple sclerosis," Nature, vol. 488, no. 7412, pp. 508-511, 2012.

[138] V. H. Guaiquil, S. Swendeman, W. Zhou et al., "ADAM8 is a negative regulator of retinal neovascularization and of the growth of heterotopically injected tumor cells in mice," Journal of Molecular Medicine, vol. 88, no. 5, pp. 497-505, 2010.

[139] E. T. Mahoney, R. L. Benton, M. A. Maddie, S. R. Whittemore, and T. Hagg, "ADAM8 is selectively up-regulated in endothelial cells and is associated with angiogenesis after spinal cord injury in adult mice," Journal of Comparative Neurology, vol. 512, no. 2, pp. 243-255, 2009.

[140] C.-W. Franzke, K. Tasanen, H. Schäcke et al., "Transmembrane collagen XVII, an epithelial adhesion protein, is shed from the cell surface by ADAMS," The EMBO Journal, vol. 21, no. 19, pp. 5026-5035, 2002.

[141] C. Mauch, J. Zamek, A. N. Abety, G. Grimberg, J. W. Fox, and P. Zigrino, "Accelerated wound repair in ADAM-9 knockout animals," Journal of Investigative Dermatology, vol. 130, no. 8, pp. 2120-2130, 2010.

[142] P. Zigrino, J. Steiger, J. W. Fox et al., "Role of ADAM9 disintegrin-cysteine-rich domains in human keratinocyte migration," Journal of Biological Chemistry, vol. 282, no. 42, pp. 30785-30793, 2007.

[143] Y. Izumi, M. Hirata, H. Hasuwa et al., "A metalloproteasedisintegrin, MDC9/meltrin- $\gamma / \mathrm{ADAM} 9$ and $\mathrm{PKC} \delta$ are involved in TPA-induced ectodomain shedding of membrane-anchored heparin-binding EGF-like growth factor," The EMBO Journal, vol. 17, no. 24, pp. 7260-7272, 1998.

[144] A. M. Bakken, C. D. Protack, E. Roztocil, S. M. Nicholl, and M. G. Davies, "Cell migration in response to the aminoterminal fragment of urokinase requires epidermal growth factor receptor activation through an ADAM-mediated mechanism," Journal of Vascular Surgery, vol. 49, no. 5, pp. 1296-1303, 2009.

[145] Y. Yang, Y. Wang, X. Zeng et al., "Self-control of HGF regulation on human trophoblast cell invasion via enhancing c-met receptor shedding by ADAM10 and ADAM17," Journal of Clinical Endocrinology and Metabolism, vol. 97, no. 8, pp. E1390-E1401, 2012.

[146] A. Schramme, M. S. Abdel-Bakky, N. Kämpfer-Kolb, J. Pfeilschifter, and P. Gutwein, "The role of CXCL16 and its processing metalloproteinases ADAM10 and ADAM17 in the proliferation and migration of human mesangial cells," Biochemical and Biophysical Research Communications, vol. 370, no. 2, pp. 311-316, 2008.

[147] Y. Shitomi, I. B. Thøgersen, N. Ito, B. Leitinger, J. J. Enghild, and Y. Itoh, "ADAM10 controls collagen signaling and cell migration on collagen by shedding the ectodomain of discoidin domain receptor 1 (DDR1)," Molecular Biology of the Cell, vol. 26, no. 4, pp. 659-673, 2015. 
[148] G. Hou, W. Vogel, and M. P. Bendeck, "The discoidin domain receptor tyrosine kinase DDR1 in arterial wound repair," Journal of Clinical Investigation, vol. 107, no. 6, pp. 727-735, 2001.

[149] S. Mechtersheimer, P. Gutwein, N. Agmon-Levin et al., "Ectodomain shedding of L1 adhesion molecule promotes cell migration by autocrine binding to integrins," Journal of Cell Biology, vol. 155, no. 3, pp. 661-673, 2001.

[150] T. Maretzky, M. Schulte, A. Ludwig et al., "L1 is sequentially processed by two differently activated metalloproteases and presenilin $/ \gamma$-secretase and regulates neural cell adhesion, cell migration, and neurite outgrowth," Molecular and Cellular Biology, vol. 25, no. 20, pp. 9040-9053, 2005.

[151] M. Klingener, M. Chavali, J. Singh et al., "N-Cadherin promotes recruitment and migration of neural progenitor cells from the SVZ neural stem cell niche into demyelinated lesions," Journal of Neuroscience, vol. 34, no. 29, pp. 9590-9606, 2014.

[152] M. A. Miller, A. S. Meyer, M. T. Beste et al., "ADAM-10 and -17 regulate endometriotic cell migration via concerted ligand and receptor shedding feedback on kinase signaling," Proceedings of the National Academy of Sciences of the United States of America, vol. 110, no. 22, pp. E2074-E2083, 2013.

[153] X. Wang, J. C. Adam, and D. Montell, "Spatially localized Kuzbanian required for specific activation of Notch during border cell migration," Developmental Biology, vol. 301, no. 2, pp. 532-540, 2007.

[154] C. Zhang, L. Tian, C. Chi et al., "Adam10 is essential for early embryonic cardiovascular development," Developmental Dynamics, vol. 239, no. 10, pp. 2594-2602, 2010.

[155] R. O. Alabi, K. Glomski, C. Haxaire, G. Weskamp, S. Monette, and C. P. Blobel, "ADAM10-dependent signaling through notch1 and notch4 controls development of organ-specific vascular beds," Circulation Research, vol. 119, no. 4, pp. 519-531, 2016.

[156] V. Caolo, G. Swennen, A. Chalaris et al., "ADAM10 and ADAM17 have opposite roles during sprouting angiogenesis," Angiogenesis, vol. 18, no. 1, pp. 13-22, 2015.

[157] K. Glomski, S. Monette, K. Manova, B. De Strooper, P. Saftig, and C. P. Blobel, "Deletion of Adam10 in endothelial cells leads to defects in organ-specific vascular structures," Blood, vol. 118, no. 4, pp. 1163-1174, 2011.

[158] K. Yang, L. Lu, Y. Liu et al., "Increase of ADAM10 level in coronary artery in-stent restenosis segments in diabetic minipigs: high ADAM10 expression promoting growth and migration in human vascular smooth muscle cells via Notch 1 and 3," PLoS ONE, vol. 8, no. 12, Article ID e83853, 2013.

[159] K. Mendelson, S. Swendeman, P. Saftig, and C. P. Blobel, "Stimulation of Platelet-Derived Growth Factor Receptor $\beta$ (PDGFR $\beta$ ) activates ADAM17 and promotes metalloproteinase-dependent cross-talk between the PDGFR $\beta$ and Epidermal Growth Factor Receptor (EGFR) signaling pathways," The Journal of Biological Chemistry, vol. 285, no. 32, pp. 25024-25032, 2010.

[160] S. Swendeman, K. Mendelson, G. Weskamp et al., "VEGFA stimulates ADAM17-dependent shedding of VEGFR2 and crosstalk between VEGFR2 and ERK signaling," Circulation Research, vol. 103, no. 9, pp. 916-918, 2008.

[161] M. Aghababaei, S. Perdu, K. Irvine, and A. G. Beristain, "A disintegrin and metalloproteinase 12 (ADAM12) localizes to invasive trophoblast, promotes cell invasion and directs column outgrowth in early placental development," Molecular Human Reproduction, vol. 20, no. 3, Article ID gat084, pp. 235-249, 2014.
[162] A. Harsha, O. Stojadinovic, H. Brem et al., "ADAM12: a potential target for the treatment of chronic wounds," Journal of Molecular Medicine, vol. 86, no. 8, pp. 961-969, 2008.

[163] C. Fröhlich, M. Klitgaard, J. B. Noer et al., "ADAM12 is expressed in the tumour vasculature and mediates ectodomain shedding of several membrane-Anchored endothelial proteins," Biochemical Journal, vol. 452, no. 1, pp. 97-109, 2013.

[164] G. Abbruzzese, S. F. Becker, J. Kashef, and D. Alfandari, "ADAM13 cleavage of cadherin-11 promotes CNC migration independently of the homophilic binding site," Developmental Biology, vol. 415, no. 2, pp. 383-390, 2016.

[165] L. Charrier, Y. Yan, A. Driss, C. L. Laboisse, S. V. Sitaraman, and D. Merlin, "ADAM-15 inhibits wound healing in human intestinal epithelial cell monolayers," American Journal of PhysiologyGastrointestinal and Liver Physiology, vol. 288, no. 2, pp. G346G353, 2005.

[166] J. Martin, L. V. Eynstone, M. Davies, J. D. Williams, and R. Steadman, "The role of ADAM 15 in glomerular mesangial cell migration," Journal of Biological Chemistry, vol. 277, no. 37, pp. 33683-33689, 2002.

[167] V. Trochon-Joseph, D. Martel-Renoir, L. M. Mir et al., "Evidence of antiangiogenic and antimetastatic activities of the recombinant disintegrin domain of metargidin," Cancer Research, vol. 64, no. 6, pp. 2062-2069, 2004.

[168] K. Horiuchi, G. Weskamp, L. Lum et al., "Potential role for ADAM15 in pathological neovascularization in mice," Molecular and Cellular Biology, vol. 23, no. 16, pp. 5614-5624, 2003.

[169] C. Sun, M. H. Wu, M. Guo, M. L. Day, E. S. Lee, and S. Y. Yuan, "ADAM15 regulates endothelial permeability and neutrophil migration via Src/ERK1/2 signalling," Cardiovascular Research, vol. 87, no. 2, pp. 348-355, 2010.

[170] D. Lu, S. Xie, M. B. Sukkar, X. Lu, M. F. Scully, and F. C. Kian, "Inhibition of airway smooth muscle adhesion and migration by the disintegrin domain of ADAM-15," American Journal of Respiratory Cell and Molecular Biology, vol. 37, no. 4, pp. 494500, 2007.

[171] J. Zhu, V. A. Siclari, F. Liu et al., "Amphiregulin-EGFR signaling mediates the migration of bone marrow mesenchymal progenitors toward PTH-stimulated osteoblasts and osteocytes," PLoS ONE, vol. 7, no. 12, Article ID e50099, 2012.

[172] R. Męzyk-Kopeć, B. Wyroba, K. Stalińska et al., "ADAM17 promotes motility, invasion, and sprouting of lymphatic endothelial cells," PLoS ONE, vol. 10, no. 7, Article ID e0132661, 2015.

[173] Q. Li, Z. Zhang, Z. Li et al., "ADAM17 is critical for multipolar exit and radial migration of neuronal intermediate progenitor cells in mice cerebral cortex," PLoS ONE, vol. 8, no. 6, Article ID e65703, 2013.

[174] T. Pasqualon, J. Pruessmeyer, V. Jankowski et al., "A cytoplasmic C-terminal fragment of syndecan-1 is generated by sequential proteolysis and antagonizes syndecan-1 dependent lung tumor cell migration," Oncotarget, vol. 6, no. 31, pp. 31295-31312, 2015.

[175] T. Pasqualon, J. Pruessmeyer, S. Weidenfeld et al., "A transmembrane C-terminal fragment of syndecan- 1 is generated by the metalloproteinase ADAM17 and promotes lung epithelial tumor cell migration and lung metastasis formation," Cellular and Molecular Life Sciences, vol. 72, no. 19, pp. 3783-3801, 2015.

[176] U. Sahin and C. P. Blobel, "Ectodomain shedding of the EGFreceptor ligand epigen is mediated by ADAM17," FEBS Letters, vol. 581, no. 1, pp. 41-44, 2007.

[177] R. A. Black, C. T. Rauch, C. J. Kozlosky et al., "A metalloproteinase disintegrin that releases tumour-necrosis factor- $\alpha$ from cells," Nature, vol. 385, no. 6618, pp. 729-733, 1997. 
[178] M. Bzowska, N. Jura, A. Lassak, R. A. Black, and J. Bereta, "Tumour necrosis factor- $\alpha$ stimulates expression of TNF- $\alpha$ converting enzyme in endothelial cells," European Journal of Biochemistry, vol. 271, no. 13, pp. 2808-2820, 2004.

[179] R. C. A. Sainson, D. A. Johnston, H. C. Chu et al., “TNF primes endothelial cells for angiogenic sprouting by inducing a tip cell phenotype," Blood, vol. 111, no. 10, pp. 4997-5007, 2008.

[180] D. Luo, Y. Luo, Y. He et al., "Differential functions of tumor necrosis factor receptor 1 and 2 signaling in ischemia-mediated arteriogenesis and angiogenesis," The American Journal of Pathology, vol. 169, no. 5, pp. 1886-1898, 2006.

[181] J. Corredor, F. Yan, C. C. Shen et al., “Tumor necrosis factor regulates intestinal epithelial cell migration by receptor-dependent mechanisms," American Journal of Physiology-Cell Physiology, vol. 284, no. 4, pp. C953-C961, 2003.

[182] Y. Jin, Y. Liu, Q. Lin et al., "Deletion of Cdc42 enhances ADAM17-mediated vascular endothelial growth factor receptor 2 shedding and impairs vascular endothelial cell survival and vasculogenesis," Molecular and Cellular Biology, vol. 33, no. 21, pp. 4181-4197, 2013.

[183] M. Romagnoli, N. D. Mineva, M. Polmear et al., "ADAM8 expression in invasive breast cancer promotes tumor dissemination and metastasis," EMBO Molecular Medicine, vol. 6, no. 2, pp. 278-294, 2014.

[184] D. Wildeboer, S. Naus, Q.-X. Amy Sang, J. W. Bartsch, and A. Pagenstecher, "Metalloproteinase disintegrins ADAM8 and ADAM19 are highly regulated in human primary brain tumors and their expression levels and activities are associated with invasiveness," Journal of Neuropathology and Experimental Neurology, vol. 65, no. 5, pp. 516-527, 2006.

[185] J. L. Fry and A. Toker, "Secreted and membrane-bound isoforms of protease ADAM9 have opposing effects on breast cancer cell migration," Cancer Research, vol. 70, no. 20, pp. 8187-8198, 2010.

[186] S. Hamada, K. Satoh, W. Fujibuchi et al., "MiR-126 acts as a tumor suppressor in pancreatic cancer cells via the regulation of ADAM9," Molecular Cancer Research, vol. 10, no. 1, pp. 3-10, 2012.

[187] A. C. B. M. Martin, A. C. F. Cardoso, H. S. Selistre-de-Araujo, and M. R. Cominetti, "Recombinant disintegrin domain of human ADAM9 inhibits migration and invasion of DU145 prostate tumor cells," Cell Adhesion \& Migration, vol. 9, no. 4, pp. 293-299, 2015.

[188] A. Mazzocca, R. Coppari, R. De Franco et al., "A secreted form of ADAM9 promotes carcinoma invasion through tumor-stromal interactions," Cancer Research, vol. 65, no. 11, pp. 4728-4738, 2005.

[189] Y. Pan, C. Han, C. Wang et al., "ADAM10 promotes pituitary adenoma cell migration by regulating cleavage of CD44 and L1," Journal of Molecular Endocrinology, vol. 49, no. 1, pp. 21-33, 2012.

[190] M. Hartmann, L. M. Parra, A. Ruschel et al., "Tumor suppressor NF2 blocks cellular migration by inhibiting ectodomain cleavage of CD44," Molecular Cancer Research, vol. 13, no. 5, pp. 879890, 2015.

[191] M. J. M. Gooden, V. R. Wiersma, A. Boerma et al., "Elevated serum CXCL16 is an independent predictor of poor survival in ovarian cancer and may reflect pro-metastatic ADAM protease activity," British Journal of Cancer, vol. 110, no. 6, pp. 1535-1544, 2014.

[192] R. Singh, N. Kapur, H. Mir, N. Singh, J. W. Lillard, and S. Singh, "CXCR6-CXCL16 axis promotes prostate cancer by mediating cytoskeleton rearrangement via Ezrin activation and $\alpha_{\mathrm{v}} \beta_{3}$ integrin clustering," Oncotarget, vol. 7, no. 6, pp. 73437353, 2016.

[193] P. Gutwein, A. Schramme, N. Sinke et al., "Tumoural CXCL16 expression is a novel prognostic marker of longer survival times in renal cell cancer patients," European Journal of Cancer, vol. 45, no. 3, pp. 478-489, 2009.

[194] B. Ma, H.-Y. Zhang, X. Bai et al., "ADAM10 mediates the cell invasion and metastasis of human esophageal squamous cell carcinoma via regulation of E-cadherin activity," Oncology Reports, vol. 35, no. 5, pp. 2785-2794, 2016.

[195] N. Woods, J. Trevino, D. Coppola, S. Chellappan, S. Yang, and J. Padmanabhan, "Fendiline inhibits proliferation and invasion of pancreatic cancer cells by interfering with ADAM10 activation and $\beta$-catenin signaling," Oncotarget, vol. 6, no. 34, pp. 3593135948, 2015.

[196] A. Stoeck, S. Keller, S. Riedle et al., "A role for exosomes in the constitutive and stimulus-induced ectodomain cleavage of L1 and CD44," Biochemical Journal, vol. 393, no. 3, pp. 609-618, 2006.

[197] M. Yang, Y. Li, K. Chilukuri et al., "L1 stimulation of human glioma cell motility correlates with FAK activation," Journal of Neuro-Oncology, vol. 105, no. 1, pp. 27-44, 2011.

[198] P. Gutwein, S. Mechtersheimer, S. Riedle et al., "ADAM10mediated cleavage of L1 adhesion molecule at the cell surface and in released membrane vesicles," The FASEB Journal: Official Publication of the Federation of American Societies for Experimental Biology, vol. 17, no. 2, pp. 292-294, 2003.

[199] Z. A. Kohutek, C. G. DiPierro, G. T. Redpath, and I. M. Hussaini, "ADAM-10-mediated N-cadherin cleavage is protein kinase C$\alpha$ dependent and promotes glioblastoma cell migration," Journal of Neuroscience, vol. 29, no. 14, pp. 4605-4615, 2009.

[200] J. Guo, L. He, P. Yuan et al., "ADAM10 overexpression in human non-small cell lung cancer correlates with cell migration and invasion through the activation of the Notchl signaling pathway," Oncology Reports, vol. 28, no. 5, pp. 1709-1718, 2012.

[201] K.-J. Hong, D.-C. Wu, K.-H. Cheng, L.-T. Chen, and W.-C. Hung, "RECK inhibits stemness gene expression and tumorigenicity of gastric cancer cells by suppressing ADAM-mediated Notchl activation," Journal of Cellular Physiology, vol. 229, no. 2, pp. 191-201, 2014.

[202] H. Qiu, X. Tang, J. Ma, K. Shaverdashvili, K. Zhang, and B. Bedogni, "Notchl autoactivation via transcriptional regulation of furin, which sustains Notch1 signaling by processing Notch1activating proteases ADAM10 and membrane type 1 matrix metalloproteinase," Molecular and Cellular Biology, vol. 35, no. 21, pp. 3622-3632, 2015.

[203] S. Liu, W. Zhang, K. Liu, B. Ji, and G. Wang, "Silencing ADAM10 inhibits the in vitro and in vivo growth of hepatocellular carcinoma cancer cells," Molecular Medicine Reports, vol. 11, no. 1, pp. 597-602, 2015.

[204] E. J. Siney, A. Holden, E. Casselden, H. Bulstrode, G. J. Thomas, and S. Willaime-Morawek, "Metalloproteinases ADAM10 and ADAM17 mediate migration and differentiation in glioblastoma sphere-forming cells," Molecular Neurobiology, 2016.

[205] A. V. Jones, D. W. Lambert, P. M. Speight, and S. A. Whawell, "ADAM 10 is over expressed in oral squamous cell carcinoma and contributes to invasive behaviour through a functional association with $\alpha \mathrm{v} \beta 6$ integrin," FEBS Letters, vol. 587, no. 21, pp. 3529-3534, 2013.

[206] R. Roy, S. Rodig, D. Bielenberg, D. Zurakowski, and M. A. Moses, "ADAM12 transmembrane and secreted isoforms 
promote breast tumor growth: a distinct role for ADAM12-S protein in tumor metastasis," Journal of Biological Chemistry, vol. 286, no. 23, pp. 20758-20768, 2011.

[207] M. C. Lydolph, M. Morgan-Fisher, A. M. Høye, J. R. Couchman, U. M. Wewer, and A. Yoneda, " $\alpha 9 \beta 1$ Integrin in melanoma cells can signal different adhesion states for migration and anchorage," Experimental Cell Research, vol. 315, no. 19, pp. 33123324, 2009.

[208] K. Ieguchi, T. Tomita, T. Omori et al., "ADAM12-cleaved ephrinAl contributes to lung metastasis," Oncogene, vol. 33, no. 17, pp. 2179-2190, 2014.

[209] A. J. Najy, K. C. Day, and M. L. Day, “ADAM15 supports prostate cancer metastasis by modulating tumor cell-endothelial cell interaction," Cancer Research, vol. 68, no. 4, pp. 1092-1099, 2008.

[210] D.-D. Dong, H. Zhou, and G. Li, "ADAM15 targets MMP9 activity to promote lung cancer cell invasion," Oncology Reports, vol. 34, no. 5, pp. 2451-2460, 2015.

[211] S. Hart, O. M. Fischer, N. Prenzel et al., "GPCR-induced migration of breast carcinoma cells depends on both EGFR signal transactivation and EGFR-independent pathways," Biological Chemistry, vol. 386, no. 9, pp. 845-855, 2005.

[212] V. Beck, H. Herold, A. Benge et al., "ADAM15 decreases integrin $\alpha v \beta 3 /$ vitronectin-mediated ovarian cancer cell adhesion and motility in an RGD-dependent fashion," International Journal of Biochemistry and Cell Biology, vol. 37, no. 3, pp. 590-603, 2005.

[213] F. Miccichè, L. da Riva, M. Fabbi et al., "Activated leukocyte cell adhesion molecule expression and shedding in thyroid tumors," PLoS ONE, vol. 6, no. 2, Article ID e17141, 2011.

[214] X. Meng, B. Hu, M. M. Hossain, G. Chen, Y. Sun, and X. Zhang, "ADAM17-siRNA inhibits MCF-7 breast cancer through EGFRPI3K-AKT activation," International Journal of Oncology, vol. 49, no. 2, pp. 682-690, 2016.

[215] O. Giricz, V. Calvo, E. A. Peterson, C. M. Abouzeid, and P. A. Kenny, "TACE-dependent TGF $\alpha$ shedding drives triplenegative breast cancer cell invasion," International Journal of Cancer, vol. 133, no. 11, pp. 2587-2595, 2013.

[216] X. Chen, L. Chen, R. Zhang et al., "ADAM17 regulates selfrenewal and differentiation of U87 glioblastoma stem cells," Neuroscience Letters, vol. 547, pp. 44-49, 2013.

[217] S. Girard, D. Brough, G. Lopez-Castejon, J. Giles, N. J. Rothwell, and S. M. Allan, "Microglia and macrophages differentially modulate cell death after brain injury caused by oxygen-glucose deprivation in organotypic brain slices," GLIA, vol. 61, no. 5, pp. 813-824, 2013.

[218] J. Wu, L. Yin, N. Jiang et al., "MiR-145, a microRNA targeting ADAM17, inhibits the invasion and migration of nasopharyngeal carcinoma cells," Experimental Cell Research, vol. 338, no. 2, pp. 232-238, 2015.

[219] H.-W. Na, W.-S. Shin, A. Ludwig, and S.-T. Lee, "The cytosolic domain of protein-tyrosine kinase 7 (PTK7), generated from sequential cleavage by a disintegrin and metalloprotease 17 (ADAM17) and $\gamma$-secretase, enhances cell proliferation and migration in colon cancer cells," Journal of Biological Chemistry, vol. 287, no. 30, pp. 25001-25009, 2012.

[220] N. V. Verbisck, É. T. Costa, F. F. Costa et al., “ADAM23 negatively modulates alpha(v)beta(3) integrin activation during metastasis," Cancer Research, vol. 69, no. 13, pp. 5546-5552, 2009.

[221] M. G. Tonnesen, X. Feng, and R. A. F. Clark, "Angiogenesis in wound healing," Journal of Investigative Dermatology Symposium Proceedings, vol. 5, no. 1, pp. 40-46, 2000.
[222] R. H. Adams and K. Alitalo, "Molecular regulation of angiogenesis and lymphangiogenesis," Nature Reviews Molecular Cell Biology, vol. 8, no. 6, pp. 464-478, 2007.

[223] G. Weskamp, K. Mendelson, S. Swendeman et al., "Pathological neovascularization is reduced by inactivation of ADAM17 in endothelial cells but not in pericytes," Circulation Research, vol. 106, no. 5, pp. 932-940, 2010.

[224] H.-I. Kwak, E. A. Mendoza, and K. J. Bayless, "ADAM17 co-purifies with TIMP-3 and modulates endothelial invasion responses in three-dimensional collagen matrices," Matrix Biology, vol. 28, no. 8, pp. 470-479, 2009.

[225] F. De Smet, I. Segura, K. De Bock, P. J. Hohensinner, and P. Carmeliet, "Mechanisms of vessel branching: filopodia on endothelial tip cells lead the way," Arteriosclerosis, Thrombosis, and Vascular Biology, vol. 29, no. 5, pp. 639-649, 2009.

[226] L. Schwettmann and H. Tschesche, "Cloning and expression in Pichia pastoris of metalloprotease domain of ADAM 9 catalytically active against fibronectin," Protein Expression and Purification, vol. 21, no. 1, pp. 65-70, 2001.

[227] M. I. Millichip, D. J. Dallas, E. Wu, S. Dale, and N. McKie, "The metallo-disintegrin ADAM10 (MADM) from bovine kidney has type IV collagenase activity in vitro," Biochemical and Biophysical Research Communications, vol. 245, no. 2, pp. 594598, 1998.

[228] M. A. Seeger and A. S. Paller, "The roles of growth factors in keratinocyte migration," Advances in Wound Care, vol. 4, pp. 213-224, 2015.

[229] A. Schönefuß, A. N. Abety, J. Zamek, C. Mauch, and P. Zigrino, "Role of ADAM-15 in wound healing and melanoma development," Experimental Dermatology, vol. 21, no. 6, pp. 437-442, 2012.

[230] D. X. Nguyen, P. D. Bos, and J. Massagué, "Metastasis: from dissemination to organ-specific colonization," Nature Reviews Cancer, vol. 9, no. 4, pp. 274-284, 2009.

[231] S. Lamouille, J. Xu, and R. Derynck, "Molecular mechanisms of epithelial-mesenchymal transition," Nature Reviews Molecular Cell Biology, vol. 15, no. 3, pp. 178-196, 2014.

[232] A. J. Najy, K. C. Day, and M. L. Day, “The ectodomain shedding of E-cadherin by ADAM15 supports ErbB receptor activation," Journal of Biological Chemistry, vol. 283, no. 26, pp. 18393-18401, 2008.

[233] M. Yilmaz and G. Christofori, "EMT, the cytoskeleton, and cancer cell invasion," Cancer and Metastasis Reviews, vol. 28, no. 1-2, pp. 15-33, 2009.

[234] J. M. David and A. K. Rajasekaran, "Dishonorable discharge: the oncogenic roles of cleaved E-cadherin fragments," Cancer Research, vol. 72, no. 12, pp. 2917-2923, 2012.

[235] K. Reiss, T. Maretzky, A. Ludwig et al., "ADAM10 cleavage of $\mathrm{N}$-cadherin and regulation of cell-cell adhesion and $\beta$-catenin nuclear signalling," The EMBO Journal, vol. 24, no. 4, pp. $742-$ 752, 2005.

[236] R. B. Hazan, G. R. Phillips, R. F. Qiao, L. Norton, and S. A. Aaronson, "Exogenous expression of $\mathrm{N}$-cadherin in breast cancer cells induces cell migration, invasion, and metastasis," Journal of Cell Biology, vol. 148, no. 4, pp. 779-790, 2000.

[237] H.-X. Wang, Q. Li, C. Sharma, K. Knoblich, and M. E. Hemler, “Tetraspanin protein contributions to cancer," Biochemical Society Transactions, vol. 39, no. 2, pp. 547-552, 2011.

[238] S. Jouannet, J. Saint-Pol, L. Fernandez et al., “TspanC8 tetraspanins differentially regulate the cleavage of ADAM10 
substrates, Notch activation and ADAM10 membrane compartmentalization," Cellular and Molecular Life Sciences, vol. 73, no. 9, pp. 1895-1915, 2016.

[239] Z. Zhou, Y.-L. Ran, H. Hu et al., “TM4SF3 promotes esophageal carcinoma metastasis via upregulating ADAM12m expression," Clinical and Experimental Metastasis, vol. 25, no. 5, pp. 537-548, 2008.

[240] T. Sasaki, K. Hiroki, and Y. Yamashita, "The role of epidermal growth factor receptor in cancer metastasis and microenvironment," BioMed Research International, vol. 2013, Article ID 546318, 8 pages, 2013.

[241] C. P. Blobel, "ADAMs: key components in egfr signalling and development," Nature Reviews Molecular Cell Biology, vol. 6, no. 1, pp. 32-43, 2005.

[242] X. Chen, L. Chen, J. Chen et al., "ADAM17 promotes U87 glioblastoma stem cell migration and invasion," Brain Research, vol. 1538, pp. 151-158, 2013.

[243] X. Zheng, F. Jiang, M. Katakowski et al., "Inhibition of ADAM17 reduces hypoxia-induced brain tumor cell invasiveness," Cancer Science, vol. 98, no. 5, pp. 674-684, 2007.

[244] I. Hernández, J. L. Moreno, C. Zandueta, L. Montuenga, and F. Lecanda, "Novel alternatively spliced ADAM8 isoforms contribute to the aggressive bone metastatic phenotype of lung cancer," Oncogene, vol. 29, no. 26, pp. 3758-3769, 2010.

[245] P. Zigrino, R. Nischt, and C. Mauch, "The disintegrin-like and cysteine-rich domains of ADAM-9 mediate interactions between melanoma cells and fibroblasts," The Journal of Biological Chemistry, vol. 286, no. 8, pp. 6801-6807, 2011.

[246] P. Gutwein, A. Stoeck, S. Riedle et al., "Cleavage of L1 in exosomes and apoptotic membrane vesicles released from ovarian carcinoma cells," Clinical Cancer Research, vol. 11, no. 7, pp. 2492-2501, 2005.

[247] O. Rosso, T. Piazza, I. Bongarzone et al., "The ALCAM shedding by the metalloprotease ADAM17/TACE is involved in motility of ovarian carcinoma cells," Molecular Cancer Research, vol. 5, no. 12, pp. 1246-1253, 2007.

[248] S. Shao, Z. Li, W. Gao, G. Yu, D. Liu, and F. Pan, "ADAM-12 as a diagnostic marker for the proliferation, migration and invasion in patients with small cell lung cancer," PLoS ONE, vol. 9, no. 1, Article ID e85936, 2014.

[249] V. H. Rao, A. Kandel, D. Lynch et al., "A positive feedback loop between HER2 and ADAM12 in human head and neck cancer cells increases migration and invasion," Oncogene, vol. 31, no. 23, pp. 2888-2898, 2012.

[250] H. D. Lee, B.-H. Koo, Y. H. Kim, O.-H. Jeon, and D.-S. Kim, "Exosome release of ADAM15 and the functional implications of human macrophage-derived ADAM15 exosomes," The FASEB Journal, vol. 26, no. 7, pp. 3084-3095, 2012.

[251] A. Kania and R. Klein, "Mechanisms of ephrin-Eph signalling in development, physiology and disease," Nature Reviews Molecular Cell Biology, vol. 17, no. 4, pp. 240-256, 2016.

[252] C. Hundhausen, A. Schulte, B. Schulz et al., "Regulated shedding of transmembrane chemokines by the disintegrin and metalloproteinase 10 facilitates detachment of adherent leukocytes," The Journal of Immunology, vol. 178, no. 12, pp. 8064-8072, 2007.

[253] Y. Shintani, S. Higashiyama, M. Ohta et al., "Overexpression of ADAM9 in non-small cell lung cancer correlates with brain metastasis," Cancer Research, vol. 64, no. 12, pp. 4190-4196, 2004.

[254] K. Horiuchi, T. Kimura, T. Miyamoto et al., "Cutting edge: TNF$\alpha$-converting enzyme (TACE/ADAM17) inactivation in mouse myeloid cells prevents lethality from endotoxin shock," Journal of Immunology, vol. 179, no. 5, pp. 2686-2689, 2007.

[255] C. Long, Y. Wang, A. H. Herrera, K. Horiuchi, and B. Walcheck, "In vivo role of leukocyte ADAM17 in the inflammatory and host responses during E. coli-mediated peritonitis," Journal of Leukocyte Biology, vol. 87, no. 6, pp. 1097-1101, 2010.

[256] D. Dreymueller and A. Ludwig, "Considerations on inhibition approaches for proinflammatory functions of ADAM proteases," Platelets, 2016.

[257] D. Dreymueller, C. Martin, T. Kogel et al., "Lung endothelial ADAM17 regulates the acute inflammatory response to lipopolysaccharide," EMBO Molecular Medicine, vol. 4, no. 5, pp. 412-423, 2012.

[258] J. A. Mathews, J. Ford, S. Norton et al., "A potential new target for asthma therapy: a disintegrin and metalloprotease 10 (ADAM10) involvement in murine experimental asthma," Allergy, vol. 66, no. 9, pp. 1193-1200, 2011.

[259] B.-B. S. Zhou, M. Peyton, B. He et al., "Targeting ADAMmediated ligand cleavage to inhibit HER3 and EGFR pathways in non-small cell lung cancer," Cancer Cell, vol. 10, no. 1, pp. 3950,2006

[260] J. S. Fridman, E. Caulder, M. Hansbury et al., "Selective inhibition of ADAM metalloproteases as a novel approach for modulating ErbB pathways in cancer," Clinical Cancer Research, vol. 13, no. 6, pp. 1892-1902, 2007.

[261] J. Chen, L. Deng, D. Dreymuller et al., "A novel peptide ADAM8 inhibitor attenuates bronchial hyperresponsiveness and Th2 cytokine mediated inflammation of murine asthmatic models," Scientific Reports, vol. 6, article 30451, 2016.

[262] M. Kveiborg, J. Jacobsen, L. Meng-Huee, H. Nagase, U. M. Wewer, and G. Murphy, "Selective inhibition of ADAM12 catalytic activity through engineering of tissue inhibitor of metalloproteinase 2 (TIMP-2)," Biochemical Journal, vol. 430, no. 1, pp. 79-86, 2010.

[263] M. A. Miller, M. L. Moss, G. Powell et al., “Targeting autocrine HB-EGF signaling with specific ADAM12 inhibition using recombinant ADAM12 prodomain," Scientific Reports, vol. 5, Article ID 15150, 2015. 


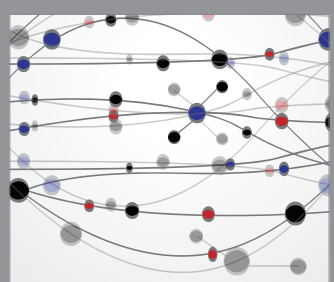

The Scientific World Journal
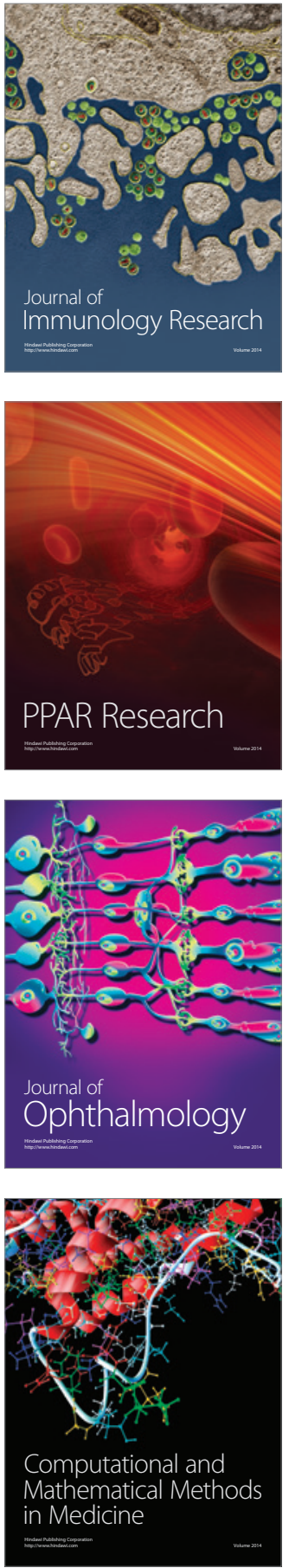

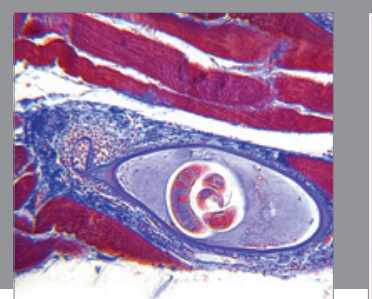

Gastroenterology Research and Practice
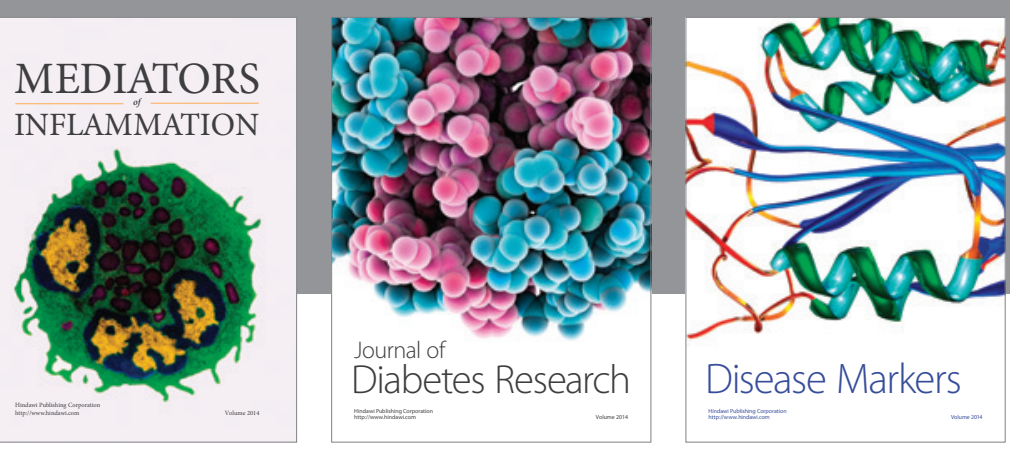

Disease Markers

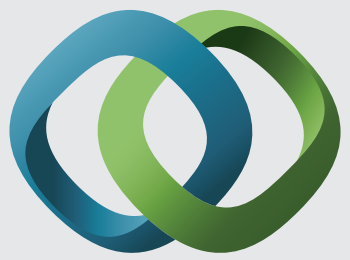

\section{Hindawi}

Submit your manuscripts at

https://www.hindawi.com
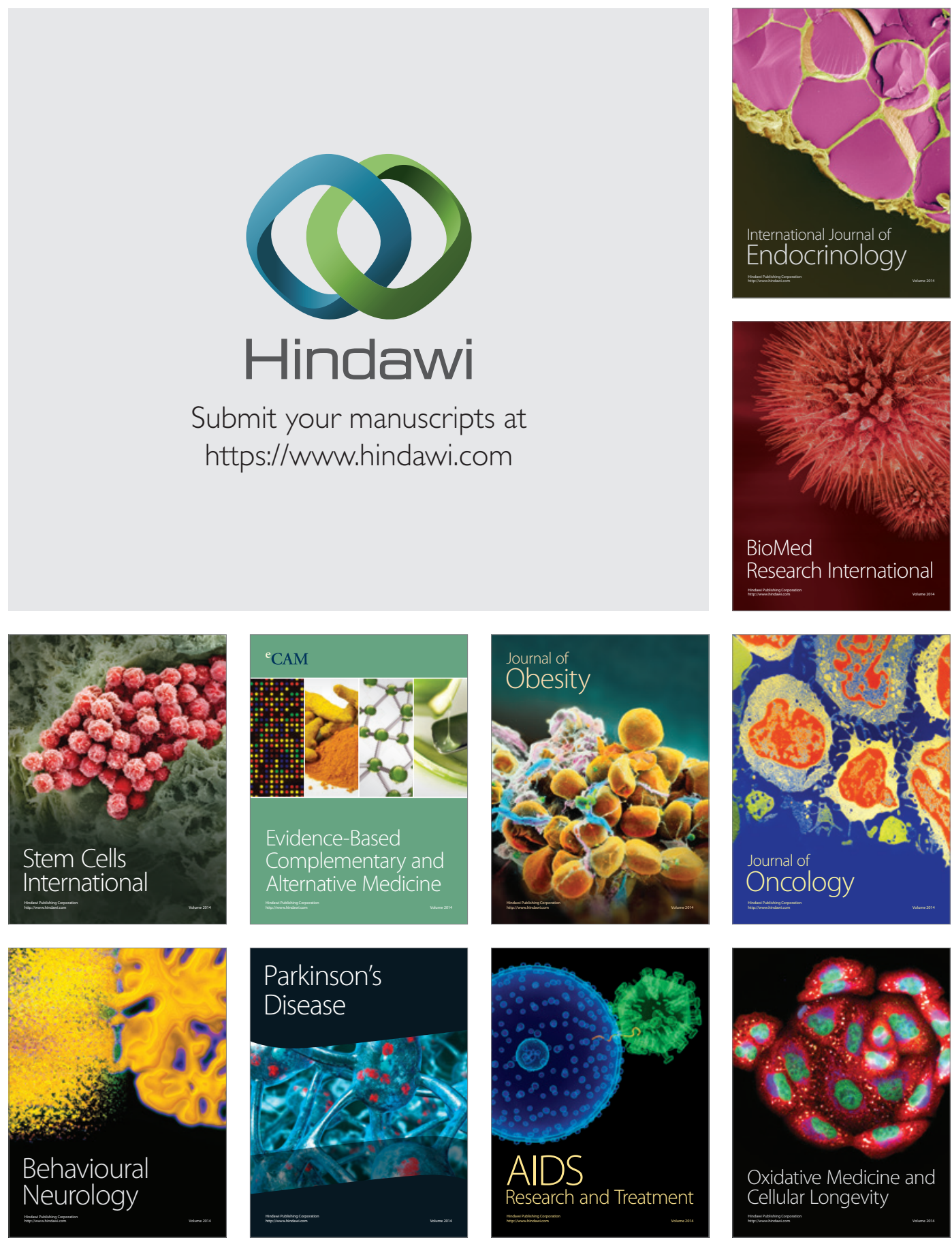